NBER WORKING PAPER SERIES

\title{
DURABLE COALITIONS AND COMMUNICATION: PUBLIC VERSUS PRIVATE NEGOTIATIONS
}

\author{
David P. Baron \\ Renee Bowen \\ Salvatore Nunnari \\ Working Paper 22821 \\ http://www.nber.org/papers/w22821 \\ NATIONAL BUREAU OF ECONOMIC RESEARCH \\ 1050 Massachusetts Avenue \\ Cambridge, MA 02138 \\ November 2016
}

We are grateful to Marina Agranov, Alessandra Casella, Giovanni Andreottola, Guillaume Frechette, Drew Fudenberg, Dimitri Landa, Thomas Palfrey, Eduard Talamas, and seminar audiences at the 2014 Mini-Conference on Experimental Economics at Caltech, the 2014 Behavioral Models in Politics Conference at Duke, the 2016 Mini-Conference on Political Economy at Stanford University, the University of Warwick, the London School of Economics, Bocconi University, the University of Padua, the 12th CSEF-IGIER Symposium on Economics and Institutions, the 2nd EIEF Political Economy Workshop, and the University of Granada for helpful comments and interesting discussions. Elliott Ash and Anselm Rink provided excellent research assistance. Nunnari acknowledges financial support from the European Research Council (Grant No. 648833) The views expressed herein are those of the authors and do not necessarily reflect the views of the National Bureau of Economic Research.

NBER working papers are circulated for discussion and comment purposes. They have not been peer-reviewed or been subject to the review by the NBER Board of Directors that accompanies official NBER publications.

(C) 2016 by David P. Baron, Renee Bowen, and Salvatore Nunnari. All rights reserved. Short sections of text, not to exceed two paragraphs, may be quoted without explicit permission provided that full credit, including $(\odot$ notice, is given to the source. 
Durable Coalitions and Communication: Public versus Private Negotiations

David P. Baron, Renee Bowen, and Salvatore Nunnari

NBER Working Paper No. 22821

November 2016

JEL No. C73,C78,C92,D71,D72,D78

\begin{abstract}
$\underline{\text { ABSTRACT }}$
We present a laboratory experiment to study the effect of communication on durable coalitions coalitions that support the same allocation from one period to the next. We study a bargaining setting where the status quo policy is determined by the policy implemented in the previous period. Our main experimental treatment is the opportunity for subjects to negotiate with one another through unrestricted cheap-talk communication before a proposal is made and comes to a vote. We compare committees with no communication, committees where communication is public and messages are observed by all committee members, and committees where communication is private and any committee member can send private messages to any other committee member. We find that the opportunity to communicate has a significant impact on outcomes and coalitions. When communication is public, there are more universal coalitions and fewer majoritarian coalitions. With private communication, there are more majoritarian coalitions and fewer universal coalitions. With either type of communication coalitions occur more frequently and last longer than with no communication. The content of communication is correlated with coalition type and with the formation and dissolution of durable coalitions. These findings suggest a coordination role for communication that varies with the mode of communication.
\end{abstract}

David P. Baron

Graduate School of Business

Stanford University

Stanford, CA 94305-5015

dbaron@stanford.edu

Renee Bowen

Graduate School of Business

Stanford University

655 Knight Way

Stanford, CA 94305

and NBER

trbowen@stanford.edu

\author{
Salvatore Nunnari \\ Bocconi University \\ Via Roentgen 1, Office 5-C2-05 \\ 20136 Milano, Italy \\ salvatore.nunnari@unibocconi.it
}




\section{Introduction}

In this paper, we present a laboratory experiment to study durable coalitions in a dynamic legislative bargaining setting where the current status quo is the policy implemented in the previous period. An endogenous status quo is a feature of many policy domains - for instance, tax rates, regulations, and entitlements - where policies can be changed by the legislature but continue in effect in the absence of a new agreement. This makes the policy-making process an intrinsically dynamic game that cannot be studied as a static competition among different constituencies, or even as a sequence of independent competitions as in a repeated game. In choosing a policy proposal and coalition partners, a policy-maker must not only consider the direct effect of the agreement but also the indirect effect of the agreement on future policy decisions. This creates incentives for a coalition to continue from one period to the next. We refer to this as a durable coalition.

Recent theoretical research on dynamic divide-the-dollar bargaining (Kalandrakis 2004, 2010, Diermeier and Fong 2011, Bowen and Zahran 2012, Battaglini and Palfrey 2012, Richter 2014, Anesi and Seidmann 2015, Baron and Bowen 2015) has produced a rich assortment of predictions. Baron and Bowen (2015) identify a large class of Markov Perfect Equilibria (MPE), and Anesi and Seidmann (2015) show that almost all allocations can be supported as stationary MPE. Anesi and Duggan (2015) show that there is a continuum of equilibria and a form of indeterminacy in more general dynamic legislative bargaining theory, even with restrictions to Markovian, stationary and weakly undominated strategies. Reviewing this literature, Binmore and Eguia (2016), referring to Anesi and Seidmann (2015), note that this "powerful result leaves us with shattered predictive power. [...] it is not the case that in real world applications anything happens in totally unpredictable fashion (budgets could be burned but are not; and in most assemblies some subsets of members are known to more frequently cooperate and coalesce with each other) and we still wish to explain and predict these coalitional patterns and bargaining outcomes in real world applications. One might conjecture that we need to include other elements $[. .$.$] into the choice set in order to$ obtain more realistic predictions."

The experiments in this paper include such "other elements" by focusing on an aspect of bargaining processes that has received little attention in models of dynamic bargaining, that of communication. Social interaction among individuals is an integral part of such processes, and it is difficult to find examples in which democratic decisions are made without people engaging in negotiations beforehand. Committee members are allowed to - and do - engage in sometimes intense communication over both proposal-making and voting. In the complete information, dynamic models studied to date there is no role for communication, and models 
with incomplete information are typically complex to study. ${ }^{1}$ Communication can play a role in complete information models with multiple equilibria by coordinating the strategies of players.

In particular, we explore experimentally how free-form communication affects bargaining outcomes and the formation and durability of coalitions in a dynamic environment. Laboratory experiments provide a direct and powerful tool for investigating the effect of communication on dynamic bargaining processes. We study the behavior of laboratory committees in a simple dynamic bargaining game with an endogenous status quo. In each period of an infinite horizon in the game, one of three committee members is randomly selected to make a proposal for the allocation of a divisible resource. The proposed allocation is implemented if it receives at least two affirmative votes (that is, a simple majority). Otherwise, the status quo policy prevails, and the resources are allocated according to that policy. The status quo policy, thus, evolves endogenously. Our main experimental manipulation is allowing players to negotiate with one another through unrestricted cheap-talk communication before a proposal is made and brought to a vote. We compare committees with no communication, committees where communication is public and all messages are observed by all committee members, and committees where communication is private and any committee member can send private messages to any other committee member.

Our main goal is to answer the following questions: Does communication affect the distribution of resources? More interestingly, does allowing committee members to communicate increase the formation and duration of coalitions? How are resources allocated among the members of a durable coalition? To what extent do these answers depend on whether communication is public or private?

We find that the opportunity to communicate has a significant impact on outcomes and coalitions. In our experimental committees, the incidence of dictatorial outcomes - where one committee member gets the lion's share of resources - is negligible. In our no communication treatment, we find $27 \%$ of majoritarian outcomes - where two committee members share most of the resources - and $71 \%$ of universal outcomes - where everyone receives a significant fraction of the resources. Private communication results in more majoritarian outcomes (51\%) relative to no communication and fewer universal outcomes (45\%). In contrast, public communication results in fewer majoritarian outcomes $(4 \%)$ relative to no communication and more universal outcomes (95\%). Durable coalitions emerge more frequently and last

\footnotetext{
${ }^{1}$ The literature on sequential legislative bargaining where a committee is disbanded once it reaches a decision has considered communication. For instance, Austen-Smith (1990) and Chen and Eraslan (2014) study theoretically the effects of cheap talk in the presence of asymmetric information between committee members.
} 
longer when communication is allowed.

We analyze the content of the messages to help understand the association of particular words, such as those related to fairness or to forming a coalition, with coalition type, size, and durability. We find that messages associated with fairness are positively correlated with universal coalitions and negatively correlated with majoritarian coalitions; that the emergence of universal coalitions is positively correlated with fairness terms and suggestion of 20-20-20 allocations, while their dissolution is positively correlated to attempts to lobby for oneself; that the emergence of majoritarian coalitions is positively correlated with messages about forming a coalition and suggestions of 30-30-0 allocations (likely from the members of the forming coalition), while their dissolution is positively correlated with suggestions of 30-30-0 allocations (likely from the member outside the dissolving coalition). Words associated with punishment, deviation, or retaliation are infrequently used and are uncorrelated with outcomes (at least, not in the way suggested by theories), suggesting that punishment strategies are not a principal explanation for universal coalitions.

This paper is related to two strands of literature. First, this paper contributes to the literature on laboratory experiments evaluating models of legislative bargaining (McKelvey 1991, Diermeier and Morton 2005, Diermeier and Gailmard 2006, Frechette, Kagel and Lehrer 2003, Frechette, Kagel and Morelli 2005a,b,c, 2012, Frechette 2009). These works focus on static environments where a given amount of resources is allocated only once. ${ }^{2}$ The only exceptions are Battaglini and Palfrey (2012) and Nunnari (2016) who investigate experimentally dynamic models of committee bargaining with an endogenous status quo in the absence of communication. A subset of the experiments presented in Battaglini and Palfrey (2012) is analogous to our treatment without communication. They find a similar distribution of outcomes, but a lower incidence of universal allocations and a higher incidence of dictatorial and majoritarian outcomes than we find. ${ }^{3}$ They do not study the effect of communication. The experiments in Nunnari (2016) are less comparable to ours, as the bargaining protocol includes players who can veto a proposal.

This paper also contributes to a growing experimental literature on the impact of unrestricted communication (Charness and Dufwenberg 2006, 2011, Brandts and Cooper 2007, Goeree and Yariv 2011, Oprea, Charness and Friedman 2014). These studies show that communication facilitates greater coordination on Pareto superior outcomes. Three recent

\footnotetext{
${ }^{2}$ Roth (1995) surveys the earlier experimental literature in bargaining. These experiments are less related as they are predominantly bilateral, static, and do not allow communication.

${ }^{3}$ There are many small differences between the two experimental designs (in the discount factor, the bargaining protocol, the sample size, and the subject pool) which may account for these differences in outcomes.
} 
experiments have allowed subjects to communicate in a multilateral bargaining setting (Agranov and Tergiman 2014a,b and Baranski and Kagel 2015). ${ }^{4}$ These papers study sequential (one-period) games that end once the resources are allocated rather than dynamic games with an endogenous status quo and thus cannot address coalition durability or the stability of allocations. They find that, when communication is allowed, outcomes in these sequential bargaining games are closer to the unique stationary subgame perfect equilibrium in which the proposer captures a disproportionate share of the resources. In contrast to this finding for sequential legislative bargaining, in our dynamic game the prediction is equal allocations for the coalition partners, and, in our experiment, public, but not private, communication strongly reduces the advantage for the proposer compared to no communication.

The reminder of the paper is organized as follows. In Section 2, we describe the dynamic divide-the-dollar game subjects play in the laboratory. In Section 3, we identify the equilibria in the existing theoretical literature for the game with no communication and state testable hypotheses regarding the introduction of communication. In Section 4, we present the experimental design. Section 5 discusses the results of the experiment, and Section 6 concludes.

\section{The Dynamic Divide-The-Dollar Game}

We consider a committee of 3 players who in each period bargain over how to divide a dollar among its members. In each period of an infinite horizon, ${ }^{5}$ the committee chooses an allocation $x^{t}=\left(x_{1}^{t}, x_{2}^{t}, x_{3}^{t}\right)$, where $x_{i}^{t} \in \mathbb{R}^{+}$for any $i=\{1,2,3\}$, and $\sum_{i=1}^{3} x_{i}^{t}=1$; that is, only efficient allocations that do not waste resources are allowed. Player $i$ derives utility $u\left(x_{i}^{t}\right)$ from the allocation he receives in period $t$, where $u$ is strictly increasing. Players are assumed to maximize the expectation of their discounted, infinite stream of utilities, where $\delta \in[0,1)$ is the common discount factor.

The bargaining protocol with which an allocation $x^{t}$ of the current period dollar is chosen is as follows. At the beginning of each period, a player is chosen at random to be the proposer and proposes an allocation $y^{t}$. The committee then votes between this allocation and the status quo. If a simple majority votes in favor of the proposal, it is accepted and $x^{t}=y^{t}$ is the implemented allocation in period $t$ and the status quo for period $t+1$. If the proposal

\footnotetext{
${ }^{4}$ The experiments in Murnighan and Roth (1977), Roth and Murnighan (1982), Rapoport and Kahan (1984), Rapoport, Erev and Zwick (1995), Valley et al. (2002), Croson, Boles and Murnighan (2003), Andreoni and Rao (2011) also explore the effect of communication on bargaining outcomes but are less related to ours, as they are bilateral and static.

${ }^{5}$ We describe how we implement an infinite horizon game in the laboratory in Section 4.
} 
is supported by less than a simple majority, it is rejected and the status quo allocation $x^{t}=x^{t-1}$ is implemented and remains the status quo for the following period. The initial status quo $x^{0}$ is exogenously selected at random.

\section{Predictions from the Theory}

The theories developed for dynamic divide-the-dollar games characterize different classes of Markov Perfect Equilibria (MPE) with various assumptions about committee size, payoffs, discount factors, selection probabilities, rules for breaking indifference, and the space of possible agreements. An MPE is a subgame perfect equilibrium in which strategies depend only on the payoff-relevant history (Maskin and Tirole 2001), which in this game is the status quo policy. Committees are composed of three players with equal agenda setting powers and do not allow for waste - that is, the sum of allocations to the three players exhausts the dollar. Given these parameters, the theories that can inform behavior in our experiment are Kalandrakis (2004), Battaglini and Palfrey (2012), Anesi and Seidmann (2015), and Baron and Bowen (2015). ${ }^{6}$

In the MPE characterized by Kalandrakis (2004), outcomes quickly converge to a rotating dictatorship with an ergodic distribution where in each period the randomly selected proposer extracts all the resources. Along the convergence path to this distribution, coalitions are majoritarian and unstable, with the proposer giving a positive allocation only to one other player, either to the cheaper or to a randomly chosen one. This MPE exists for any degree of players' patience.

In the Markov Logit Quantal Response Equilibria (MLE) numerically computed by Battaglini and Palfrey (2012), ${ }^{7}$ outcomes converge to a rotating dictatorship if players' utilities are linear. If players' utilities are strictly concave, players are averse to sequences of outcomes in which the status quo changes and the incentives for more symmetric allocations among players are stronger. Battaglini and Palfrey (2012) present numerical results for highly risk averse players: starting from a dictatorial allocation, the committee moves to a minimal-winning allocation where two players divide the dollar equally or, less frequently,

\footnotetext{
${ }^{6}$ Diermeier and Fong (2011) assume a persistent agenda setter. The MPE in Richter (2014) crucially depends on the possibility of waste. The MPEs in Kalandrakis (2009) and Bowen and Zahran (2012) exist only for, respectively, five or more and seven or more players. Therefore, the predictions from these four papers cannot inform behavior in our experiment.

${ }^{7}$ In Battaglini and Palfrey (2012) equilibria are computed as the limit of MLEs by gradually reducing noise in the players reaction functions. In the logit version of quantal response equilibrium, each player at each information set uses a behavioral strategy where the log probability of choosing each available action is proportional to its continuation payoff.
} 
to a universal allocation. These minimal-winning allocations are highly persistent but not absorbing, as the committees transition to a universal allocation around $20 \%$ of the time. Once a universal allocation is reached, it is essentially an absorbing state (the probability of leaving this state is approximately 2\%). The risk aversion assumed by Battaglini and Palfrey (2012) to obtain convergence to a universal allocation is too extreme to be plausible in the experiment, so their relevant predictions are rotating dictatorships or rotating minimal winning coalitions. ${ }^{8}$

The equilibria in Anesi and Sedimann (2015) and Baron and Bowen (2015) are driven by what Diermeier et al. (2008) refer to as the fear of exclusion: a player accepts a proposal in the current period because of fear that if he rejects the proposal he may be excluded from the coalition formed in the next period. Anesi and Seidmann (2015) show that, as players become increasingly patient, almost any allocation - the exceptions being dictatorial and universal allocations - is possible with stationary MPE proposals, what they call simple solutions, that depend on the identity of players and include a punishment for each of the other players. The result that almost all outcomes can be supported requires that the values of the game differ among players and that allocations include waste. Baron and Bowen (2015) characterize stationary MPEs that support allocations with an equal opportunity property that implies that the values of the game are the same for all players. With three players, no waste and for a sufficiently high $\delta$, these MPEs support minimal-winning coalitions with allocations of the form $(c, c, 1-2 c)$ for all $c \in\left(\frac{1}{3}, \frac{1}{2}\right]$. Allocations of this form are also the only simple solutions in Anesi and Seidmann (2015) and in Anesi and Duggan (2015) with equal values of the game and efficient allocations, as in the experiment. The equilibrium outcomes in Anesi and Seidmann (2015) and Baron and Bowen (2015) are reached in one bargaining period and are persistent. ${ }^{9}$

In the experiment we have 60 tokens to be allocated each period with $\delta=0.8$, so a feasible allocation is a triplet of integers between 0 and 60 that sum to 60 . With this discount factor the outcomes predicted in Anesi and Seidmann and Baron and Bowen are

\footnotetext{
${ }^{8}$ They specify a utility function $u\left(x_{i}\right)=\frac{1}{1-\gamma} x_{i}^{1-\gamma}$ with $\gamma=0.95$. The certainty equivalent for a $50-50$ lottery with payoffs 0 and 3 , the range of payoffs in our experiment, is 0.0000028 .

${ }^{9}$ The equilibria in these theories depend importantly on how indifference in voting is broken. Kalandrakis (2004) assumes that a player votes for a proposal when indifferent between it and the status quo, and Battaglini and Palfrey (2012) assume that a player votes for the proposal with probability 0.5 when indifferent. Anesi and Seidmann (2015) assume that when indifferent the players vote for the status quo when it is in a simple solution, and for the proposal when the status quo is not in a simple solution. Baron and Bowen (2015) assume that players vote for the status quo when indifferent. The indifference rules in the latter two theories yield stability rather than rotation. For comparability the predictions here for the Baron and Bowen model are based on the indifference rule in Anesi and Seidmann (2015).
} 


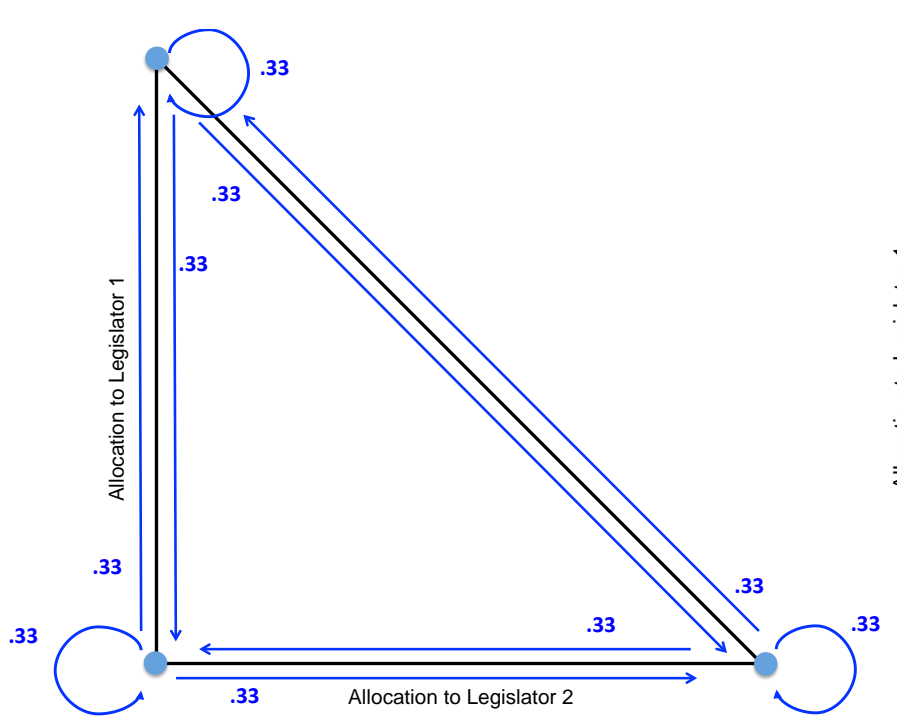

(a)

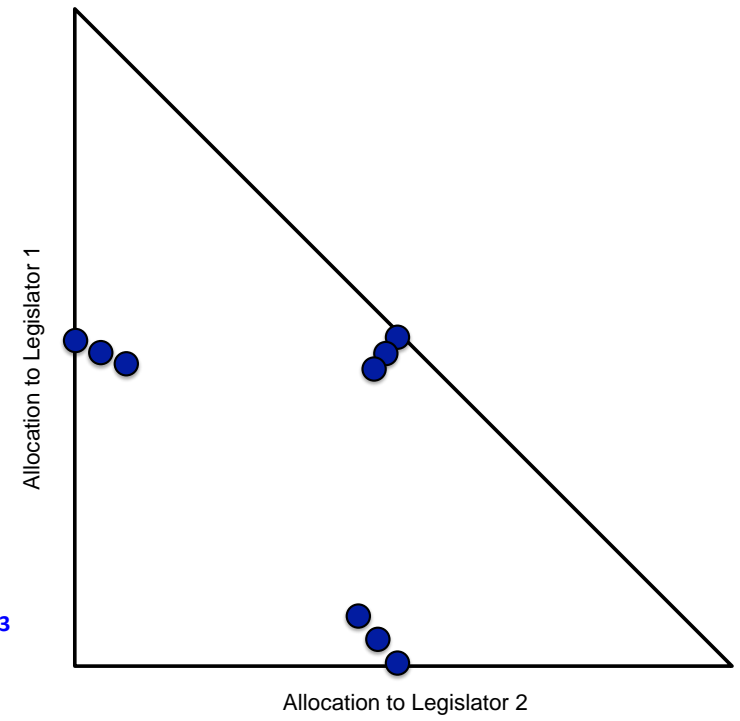

(b)

Figure 1: Panel (a): Stationary distribution induced by MPE in Kalandrakis (2004) with $\delta=0.8$ and Battaglini and Palfrey (2012) with $\gamma=0, \delta=0.8$. Panel (b): Absorbing outcomes according to different MPEs with $\delta=0.8$ in Anesi and Seidmann (2015) and Baron and Bowen (2015).

$(30,30,0),(29,29,2),(28,28,4)$ and their permutations. ${ }^{10}$ Figure 1 shows the predicted outcomes for each paper whose theory applies to our experimental setting.

Neither Anesi and Seidmann (2015) nor Baron and Bowen (2015) predict that the universal allocation $(20,20,20)$ is supported in an efficient MPE because there is no exclusion risk. ${ }^{11}$ This allocation can be supported in a subgame perfect equilibrium using playerspecific punishments in which a player who deviates from the universal allocation receives 0 thereafter and the other two players receive 30 each and hence have an incentive to punish. The universal allocation can also be supported in an MPE if players have sufficiently altruistic preferences. ${ }^{12}$ Analysis of the communication among experimental subjects reveals the frequent use of words related to fairness, which is consistent with altruism or a norm of

\footnotetext{
${ }^{10}$ If the values of the game can differ among players, additional allocations can be supported in an MPE. A simple solution, $S S$, is a triple of policies, and equilibrium allocations to individual players can be as different as in $S S=\{(34,26,0),(8,26,26),(34,0,26)\}$, for which the values of the game are $\left(\frac{78}{3}, \frac{52}{3}, \frac{52}{32}\right)$ for the three players. There is little reason to believe that subjects in the experiment view themselves or others as advantaged or disadvantaged in the game, which is needed if the values of the game implemented in the experiment are different. Note that in the simple solution above player 3 accepts proposals $(8,26,26)$ and $(34,0,26)$ but not proposals $(0,34,26)$ or $(26,8,26)$. There is also little reason to believe that a player views the other anonymous and randomly selected players as different.
}

${ }^{11}$ Richter (2014) shows that the universal allocation can be supported as an MPE if there is a threat created by the possibility of waste off the equilibrium path.

${ }^{12}$ If preferences of player $i$ are $U_{i}(x)=x_{i}+\theta \sum_{j=1, j \neq i}^{n} x_{j}, \theta \geq 1$, the universal allocation is supported in an MPE, as shown in Baron (2016). 
fairness being present among them. The presence of universal allocations is not correlated with discussions of the history of play, including punishment, deviation, or retaliation, which is inconsistent with universal allocations supported by punishment strategies.

The dynamic bargaining games studied in the literature all assume complete information with no role for communication. In the theories there is a set of subgame perfect equilibria, including rotating dictatorships, universal, minimal winning, and surplus coalitions, and symmetric and asymmetric allocations among coalition members. Moreover, players can have differing utility functions, which allows for additional equilibria. This leaves the questions of which, if any, of these equilibria would be played in a setting in which players may not know the equilibrium strategies or which strategies the other players will use. The experiment provides evidence on what players do as a function of communication that could support coordination on particular equilibria. Our main experimental treatment is the ability of players to negotiate with one another through unrestricted cheap-talk communication. Our hypothesis is that communication serves as a coordination device and can make some outcomes focal. For example, the MPE in Anesi and Seidmann (2015) with equal values of the game and Baron and Bowen (2015) are particularly simple, are identity free, exhibit outcome and coalition stability, provide equal allocations to coalition members, and could be coordinated on through straightforward communication between the proposer of the coalition and potential coalition partners.

If subjects have altruistic preferences or follow a norm, such as a norm of fairness, the effect of communication on outcomes could depend on whether that communication is private or public. For example, suggesting a minimal winning coalition with public communication could be viewed as an expression of selfish preferences or a violation of the norm of fairness, resulting in rejection of the suggestion; when communication is private, only two subjects know of the suggestion and, hence, whether preferences might be selfish or a norm of fairness violated. This reasoning suggests a hypothesis that private communication facilitates coordination on minimal winning coalitions and public communication inhibits coordination on minimal winning coalitions. The frequency of minimal winning coalitions then should increase with private communication and decrease with public communication, relative to no communication. This is consistent with a hypothesis that public communication facilitates coordination on universal coalitions. This hypothesis is consistent with the findings of Diermeier et al. (2008) that in face-to-face, one-shot, protocol-free negotiations, "proto-coalition members appear to be embarrassed to "shut the door" on the third party permanently, as this may be considered socially unacceptable behavior" (p. 498). Our experiment finds that this may also be the case in anonymous, computer-mediated, dynamic, structured bargaining. ${ }^{13}$

\footnotetext{
${ }^{13}$ Beyond these differences in the game and in the treatment implementation, the participants to the
} 


\section{Experimental Design}

The experiments were conducted at the Columbia Experimental Laboratory for Social Sciences (CELSS) in March 2014 using students from Columbia University. Subjects were recruited from a database of volunteer subjects. Six sessions were run with a total of 120 subjects, and no subject participated in more than one session. All the interactions between subjects were performed through computers. ${ }^{14}$ The 60 tokens available to each committee in each period correspond to US\$3.

In all committees the discount factor was $\delta=0.8$. Discounting was induced by a random termination rule: after each period of the same game, a random number between 0 and 100 was drawn by the computer with the outcome determining whether the game continued to another period (with probability $\delta$ ) or was terminated (with probability $1-\delta$ ). This is a standard technique used in the experimental literature to preserve the incentives of infinite horizon games in the laboratory (Roth and Murnighan 1978, Palfrey and Rosenthal 1994, Dal Bo 2005, Duffy and Ochs 2009).

We use a novel implementation of this methodology introduced by Frechette and Yuksel (2013), the block random termination rule: subjects play as in the standard random termination rule but in blocks of four periods. Within a block subjects receive no feedback about whether the game has continued to that period, and they make choices that will be payoff-relevant contingent on the game actually having reached that point. After each block of four periods, subjects are told whether the game ended within that block and, if so, in what period; otherwise, they are told that the game has not ended yet, and they start a new block. Subjects are paid for periods only up to the end of their game, and all decisions for subsequent periods within that block are void with respect to payment. As shown by Frechette and Yuksel (2013), this alternative implementation of an infinitely repeated game results in the same theoretical properties and in similar laboratory behavior as the standard random termination rule. This implementation is appealing for studying the formation and duration of coalitions, because it allows us to observe subjects' behavior for a greater number of periods. In the empirical analysis, we use all available data, including data from periods that, ex post, were not used in determining payments to subjects. The methodology ensures that every period played (including periods that, ex post, are not used to determine payments) have the same incentives.

experiments presented by Diermeier et al. (2008) were confronted with a hypothetical-choice situation: they "were not paid and did not receive special course credit contingent on negotiation success" (p. 490).

\footnotetext{
${ }^{14}$ Sample instructions are provided in Appendix E. The computer program used in the experiment was an extension to the open source software Multistage.
} 
Sessions were conducted with a minimum of 15 subjects and a maximum of 24 subjects, divided into committees of 3 members each. Committees stayed the same throughout the periods of a given game, and subjects were randomly rematched into committees between games. Each game corresponded to one play of the infinitely repeated game, using the block termination rule. ${ }^{15}$

Our main experimental manipulation is the opportunity for subjects to negotiate with one another through unrestricted cheap-talk communication before a proposal is made and comes to a vote. We compare committees with no communication, committees where communication is public and messages are observed by all committee members, and committees where communication is private and any committee member can send private messages to any other committee member. We conduct two sessions where communication is not allowed, two where only public communication is allowed, and two where only private communication between two committee members is allowed.

At the beginning of each game, subjects are randomly divided into committees of three members each. In each committee, subjects are assigned to be Committee Member 1, Committee Member 2, or Committee Member 3. This member assignment remains the same for all periods of a game. For each committee, an initial status quo is randomly chosen by the computer, using a uniform distribution on the set of feasible allocations. The drawing of an initial status quo is independent across games and across committees. ${ }^{16}$ At the beginning of each period, one of the three members is randomly selected to be the proposer, and his committee member number is revealed to the entire committee. When communication is not allowed, the proposer proposes an allocation that is observed by all members of the committee with the shares to each member clearly indicated. Then, all members of the committee simultaneously vote to accept or reject the proposed allocation. If the allocation is supported by a simple majority of members, it passes, determines the distribution of the 60 tokens in that period, and becomes the new status quo allocation for the next period. If the allocation is rejected, the shares in this period are determined by the status quo, which becomes the status quo for the next period. After each period, subjects observe how each member in the committee voted and how this determines committee members' payoffs for this period and the status quo allocation for the following period. After each game, subjects are randomly re-matched to form new committees and assigned new committee member numbers. Each

\footnotetext{
${ }^{15}$ The length of the games ranged from 4 to 24 periods in blocks of 4 .

${ }^{16}$ The initial status quo is given exogenously to preserve symmetry of the bargaining protocol with the other periods of the game. Note that the theories discussed in the previous section do not depend on the initial status quo. Moreover, in Appendix C, we show that the exogenous status quo at the beginning of the game does not anchor outcomes beyond the first period, in particular, it does not affect the committee allocation in the second period of the same game.
} 


\begin{tabular}{ccccccc}
\hline \hline Session & Treatment & $\mathbf{n}$ & $\delta$ & Games & Subjects & Committees \\
\hline 1 & Public Communication & 3 & 0.8 & 4 & 21 & 28 \\
2 & Public Communication & 3 & 0.8 & 4 & 21 & 28 \\
3 & Private Communication & 3 & 0.8 & 4 & 21 & 28 \\
4 & Private Communication & 3 & 0.8 & 4 & 24 & 32 \\
5 & Baseline (No Communication) & 3 & 0.8 & 4 & 18 & 24 \\
6 & Baseline (No Communication) & 3 & 0.8 & 4 & 15 & 20 \\
\hline \hline
\end{tabular}

Table 1: Experimental design

subject plays four games.

In the Baseline treatment, no communication was allowed. The Public Communication and Private Communication treatments are similar to the Baseline treatment except for one feature. After the proposer was selected and his committee member number revealed but before the proposer submits his proposal, members of the committee can communicate with each other using a chat tool. In the Private Communication treatment, subjects can send private messages that are delivered only to a particular member. When a committee member sends a message to another, the third committee member does not know the content of this communication nor the fact that a message was sent. ${ }^{17}$ In the Public Communication treatment, subjects were only allowed to send messages that were received by all the other members of their committee. The duration of the communication was in the hands of the proposer, and the chat tool was disabled when the proposer submitted his proposal for a vote or after 120 seconds had passed. The software recorded all the messages sent by subjects during the communication stage. Table 1 summarizes the details of all the treatments.

\section{$5 \quad$ Experiment Results}

In this section we first compare the allocation of resources among committee members for the three treatments. Second, we identify durable coalitions and study whether their emergence and duration are affected by communication. Finally, we explore the content of conversations to shed light on the mechanism behind the differences in allocations and coalitions. To allow for learning in the initial repetition of our infinite horizon divide-the-dollar game, we present and analyze the data from games 2 through 4 in each session. Unless stated explicitly, our statements about statistical significance are robust to considering the whole sample (that is, including data from the first game).

\footnotetext{
${ }^{17}$ In the private communication treatment a committee member could send the same message to each other committee member, but one other member would not know the other had received the message.
} 


\begin{tabular}{lccc}
\hline \hline Allocation Type & Baseline & Private & Public \\
\hline DICTATORIAL & $1 \%$ & $5 \%^{\dagger}$ & $1 \%$ \\
MAJORITARIAN & $27 \%$ & $51 \%^{\dagger}$ & $4 \%^{\dagger}$ \\
Even & $11 \%$ & $34 \%^{\dagger}$ & $2 \%^{\dagger}$ \\
Uneven & $16 \%$ & $17 \%$ & $2 \%^{\dagger}$ \\
UNIVERSAL & $71 \%$ & $45 \%^{\dagger}$ & $95 \%^{\dagger}$ \\
Even & $49 \%$ & $31 \%^{\dagger}$ & $90 \%^{\dagger}$ \\
Uneven & $22 \%$ & $14 \%^{\dagger}$ & $5 \%^{\dagger}$ \\
Observations & 328 & 472 & 252 \\
\hline \hline
\end{tabular}

Table 2: Frequency of allocation types by treatment. $\dagger$ : significant difference with baseline according to Wilcoxon-Mann-Whitney tests $(p<0.05)$. An observation is a committees in a period.

\subsection{Distribution of Resources}

We begin the analysis of the experimental results by examining the bargaining outcomes, that is, the allocation of resources (60 tokens) at the end of a period. We define as "Dictatorial" those allocations that give at least 50 tokens (that is, $83 \%$ of the 60 tokens) to a single committee member and define as "Universal" allocations that give at least 10 tokens (that is, $17 \%$ of the 60 tokens) to every member of the committee. All other allocations give a significant fraction of the tokens to exactly two committee members (that is, to a minimal winning coalition), which we label as "Majoritarian." 18 In the latter two categories, we highlight allocations that give members an even number of tokens. For the Universal allocations this correspond to the allocation $(20,20,20)$; for the Majoritarian allocations this includes all allocations of the form $(b, b, 60-2 b), b \in\{26, \ldots, 30\}$. Table 2 presents the distribution of allocation types for the three treatments.

FINDING 1: Private communication makes Majoritarian allocations - in particular, those with even sharing between two committee members - more likely and Universal allocations less likely. Public communication makes Majoritarian allocations less likely, and Universal allocations - in particular, those with even sharing among all committee members - more likely.

Table 2 shows that the frequency of Majoritarian allocations is $27 \%$ when communication is not allowed, $51 \%$ when only private communication is allowed, and $4 \%$ when public communication is allowed. The frequency of Universal allocations is $71 \%$ with no commu-

\footnotetext{
${ }^{18}$ These are the definitions used by Battaglini and Palfrey (2012).
} 


\begin{tabular}{|c|c|c|}
\hline \multirow{2}{*}{$\begin{array}{l}\text { Dependent Variable: } \\
\text { Share to } i \text { in Status Quo }\end{array}$} & Share Allocated & to Member $i$ \\
\hline & $0.12^{*}$ & $0.13^{*}$ \\
\hline & $(0.07)$ & $(0.07)$ \\
\hline \multirow[t]{2}{*}{$i$ Proposer } & $6.88^{* * *}$ & $6.75^{* * *}$ \\
\hline & $(1.49)$ & $(1.46)$ \\
\hline$i$ Proposer $*$ Private & $\begin{array}{c}-0.95 \\
(1.93)\end{array}$ & \\
\hline$i$ Proposer $*$ Public & & $\begin{array}{c}-5.89^{* * *} \\
(1.51)\end{array}$ \\
\hline Constant & $\begin{array}{c}15.04^{* * *} \\
(1.23)\end{array}$ & $\begin{array}{c}15.11^{* * *} \\
(1.18)\end{array}$ \\
\hline Treatments & Base \& Private & Base \& Public \\
\hline Observations & 2,400 & 1,740 \\
\hline Pseudo R-Squared & 0.0504 & 0.0211 \\
\hline
\end{tabular}

Table 3: Tobit regressions. Standard errors clustered by committees in parentheses. ${ }^{*} p<0.10,{ }^{* *} p<0.05$, $* * * p<0.01$. An observation is a committee member in a period. Other regressors: treatment dummies and interaction with share in status quo.

nication, $45 \%$ with private communication, and $95 \%$ with public communication. ${ }^{19}$ These differences are statistically significant. ${ }^{20}$ The difference in the incidence of Majoritarian allocations between the treatment with no communication and the treatment with private communication is due to the difference in Majoritarian allocations with equal sharing between two committee members, which triples (from $11 \%$ to $34 \%$ ). Strikingly, subjects who communicate publicly divide resources evenly (that is, 20 tokens each) $90 \%$ of the time.

Private communication increases the frequency of allocations with even distribution among the members of a Majoritarian coalition, which is consistent with the prediction of Baron and Bowen (2015) and supportive of the even distribution allocations in Anesi and Seidmann (2015). While Dictatorial allocations are more frequent when subjects can communicate privately, the findings for all treatments are inconsistent with a rotating dictator equilibrium as in Kalandrakis (2004) and Battaglini and Palfrey (2012) (for a linear utility function), where allocations belong to the Dictatorial region in almost every period.

The results from Table 2 suggest that the opportunity to communicate supports coordi-

\footnotetext{
${ }^{19}$ In Appendix A we show that our results are robust to a different definition of Majoritarian and Universal allocations: at least 15 tokens (that is, $25 \%$ of the tokens) to every member as Universal; at least 20 tokens (that is, $33 \%$ of the tokens) to two members and less than 15 to the other as Majoritarian. The distribution is similar: pooling together all treatments, Majoritarian and Universal allocations are, respectively, $32 \%$ and $65 \%$ with the original definition; $39 \%$ and $55 \%$ with this alternative definition.

${ }^{20}$ When using the whole sample, the fraction of Dictatorial allocations is significantly higher in public communication than in the baseline (3\% vs. 1\%); the fraction of Majoritarian Even in Public Communication is indistinguishable from the Baseline ( $9 \%$ vs. $12 \%)$. All other comparisons are unchanged.
} 
nation on coalitions in which members share the resources more evenly than in the baseline treatment where no communication is allowed. What does this communication mean for the allocation to the proposer relative to a non-proposer, or the proposer's advantage?

\section{FINDING 2: Public communication decreases the proposer's advantage. Private communication does not affect the proposer's advantage.}

Table 3 presents Tobit regressions where the dependent variable is the share allocated to a committee member at the end of a period. This amount depends positively on the share to a committee member in the status quo at the beginning of that period. It also depends on the role a committee member has in that period, with proposers receiving more than non-proposers. Interestingly, this proposer's advantage is unchanged with private communication and sharply dampened by public communication. ${ }^{21}$ This result is in stark contrast with experiments on the static bargaining game à la Baron and Ferejohn (1989) studied by Agranov and Tergiman (2014a,b) and Baranski and Kagel (2015), where, under simple majority, the proposer gains from the introduction of either type of communication due to the reduction in uncertainty and to the competition among potential coalition partners for inclusion in the coalition. ${ }^{22}$ This is consistent with a different mechanism that might be at play in the dynamic game studied here. In the dynamic game we study, a proposer has an incentive to propose an allocation that the coalition partner(s) will support in future periods, which requires the proposer to allocate evenly among coalition members. In the static game there are no future periods, and the proposer can capture 44 tokens, allocating 16 to one other subject.

In both the static legislative bargaining game and our dynamic game, the introduction of communication results in observed allocations being closer to the allocations predicted by the theory. In the Baron and Ferejohn (1989) game there is a unique stationary SPE, and the question is whether play is according to that equilibrium. In our dynamic legislative bargaining game, multiple equilibria are supported by stationary MPEs. Among these are equilibria in which proposers can sacrifice proposal power for durability of their coalition, as predicted by Anesi and Seidmann (2015) and Baron and Bowen (2015). In the next section, we explore the extent to which coalitions form, their duration, and how they are affected by the two modes of communication. This analysis may help refine the theory for dynamic

\footnotetext{
${ }^{21}$ One possible explanation is that subjects during the first game learn to coordinate on equal division, and hence communication does not affect the shares in games 2-4. This explanation, however, leaves the question of why there is no effect with private communication and a significant effect with public communication.

${ }^{22}$ These experiments are with committees composed of five members. In the communication treatments of Agranov and Tergiman $(2014 a, b)$, subjects can send a message to any subset of members in their committee (that is, they can send messages both privately and publicly). Baranski and Kagel (2015) use two communication treatments, analogous to our private and public communication.
} 
legislative bargaining games, and, specifically, help to understand which coalitions are focal with communication.

\subsection{Coalition Formation and Duration}

In Table 2 we classified outcomes using categories based on the allocation and not by which subjects received the tokens. For example, both $(30,30,0)$ and $(0,30,30)$ were classified as majoritarian allocations, but a majoritarian coalition is not present unless the same subjects receive the 30 tokens in two consecutive periods. We define a durable coalition as a committee that continues from one period to the next with the same allocation. ${ }^{23}$ To investigate the emergence and persistence of durable coalitions, we study the evolution of allocations over time. Since the status quo in the first period of a game is exogenous, we exclude the first period from the analysis in this subsection (that is, we only include periods whose status quo is endogenous). ${ }^{24}$

\begin{tabular}{|c|c|c|c|}
\hline \multirow[b]{2}{*}{ Allocation Type $(t-1)$} & \multicolumn{3}{|c|}{$\operatorname{Pr}\left[\right.$ Allocation $_{(t)}=$ Allocation $\left._{(t-1)}\right]$} \\
\hline & Baseline & Private & Public \\
\hline DICTATORIAL & $0.33(3)$ & $0.38(21)$ & $0.00(1)$ \\
\hline MAJORITARIAN & $0.17(83)$ & $0.58^{\dagger}(218)$ & $0.00(7)$ \\
\hline UNIVERSAL & $0.68(209)$ & $0.69(188)$ & $0.93^{\dagger}(202)$ \\
\hline Observations & 295 & 427 & 210 \\
\hline
\end{tabular}

Table 4: Persistence of allocation by treatment and allocation type. Number of observations for each allocation type and treatment in parentheses. $\dagger$ : significant difference with baseline according to WilcoxonMann-Whitney tests $(p<0.05)$. An observation is a committees in a period.

\section{FINDING 3: Private communication increases the persistence of Majoritarian allocations. Public communication increases the persistence of Universal alloca- tions.}

\footnotetext{
${ }^{23}$ In Appendix B we show that the results are robust to a different, less stringent, definition of durable coalitions. We define a weak durable coalition as a committee that channels resources to the same subset of members as in the previous period. To identify weak durable coalitions, Dictatorial allocations are classified as one of three types (those that give most of the resources, respectively, to member 1, 2, or 3), Majoritarian allocations are classified as one of three types (those where the resources are divided between members 1 and 2; members 1 and 3; and members 2 and 3), and Universal allocations are classified as a single type. A weak durable coalition then is a committee that continues from one period to the next with an allocation of the same type.

${ }^{24}$ The results presented in this subsection (and in the following subsection for durable coalitions) are unchanged if we include the first period in the analysis of status quo persistence and if we allow a durable coalition to start in the first period of a game.
} 
For each of the three treatments, Table 4 presents the probability that an allocation persists from one period to the next, i.e., a durable coalition is present. The same Majoritarian allocation persists $18 \%$ of the time without communication, $58 \%$ with private communication and $0 \%$ with public communication. The difference between private communication and the baseline is statistically significant. The same Universal allocation persists $67 \%$ of the time without communication, $69 \%$ with private communication and $93 \%$ with public communication. The difference between public communication and the baseline is statistically significant. ${ }^{25}$

Private communication, thus, is associated with coordinating on Majoritarian allocations and sustaining a two-subject coalition over time. Public communication is associated with coordinating on Universal allocations and sustaining a three-subjects coalition over time. This finding suggests that subjects are less willing to participate in coalitions that disadvantage one subject when communication is public and exposed to all subjects. This is consistent with the hypothesis that private communication facilitates coordination on Majoritarian coalitions and public communication facilitates coordination on Universal coalitions when a norm of fairness is present among subjects. This interpretation is supported by the subjects' use of words corresponding to fairness as discussed in Section 5.3.

Finally, we investigate how the duration of a coalition is affected by the opportunity to communicate. Duration is defined as the number of periods that a coalition continues with the same allocation, so a coalition that begins in period 2 and ends after period 4 has a duration of 2 . In the baseline treatment there are 44 coalitions in 33 committees; in the private communication treatment there are 78 coalitions in 45 committees; and with public communication there are 41 coalitions in 42 committees. Note that in each of the treatments there can be more than one coalition formed in a single committee. To investigate duration, we focus on Majoritarian and Universal coalitions. ${ }^{26}$ In the 78 committees from the baseline and private communication treatments, there are 56 Majoritarian coalitions and 66 Universal coalitions. In the 75 committees from the baseline and public communication treatments, there are 72 Universal coalitions. Since with Public Communication there are no Majoritarian coalitions, we do not estimate the effect of this treatment on the duration of Majoritarian coalitions.

\section{FINDING 4: Private communication increases the duration of Majoritarian}

\footnotetext{
${ }^{25}$ When using the whole sample, Majoritarian allocations are more likely to persist from one period to the next in Public Communication than in the Baseline (44\% vs. 22\%). The other comparisons are unchanged.

${ }^{26}$ We exclude persistent dictatorial allocations, which are approximately $1 \%$ of the data. A dictatorial allocation can persist with probability one-third, because when the dictator is selected as the proposer he can propose the status quo and the vote is then immaterial.
} 


\begin{tabular}{lccc}
\hline \hline & \multicolumn{3}{c}{ Dependent Variable: Coalition Duration } \\
\hline Private Communication & $1.94^{* * *}$ & -1.16 \\
Public Communication & $(0.45)$ & $(1.02)$ & \\
& & & $2.91^{* * *}$ \\
Game Length & & $0.68)$ \\
& -0.03 & $(0.13)$ & $0.65^{* * *}$ \\
Constant & $(0.06)$ & $2.32^{*}$ & $(0.14)$ \\
& $1.43^{*}$ & $(1.38)$ & $-2.31^{* *}$ \\
Treatments & $(0.74)$ & $1.13)$ \\
Coalition Type & Base \& Private & Base \& Private & Base \& Public \\
Observations & Majoritarian & Universal & Universal \\
$R^{2}$ & 56 & 66 & 72 \\
\hline \hline
\end{tabular}

Table 5: OLS regressions. Standard errors clustered by committees are in parentheses. ${ }^{*} p<0.10$, ${ }^{* *}$ $p<0.05,{ }^{* * *} p<0.01$. An observation is a coalition that lasts for at least one period.

\section{coalitions; public communication increases the duration of Universal coalitions.}

With the block random termination design a coalition exogenously ends when the block during which the game ends is terminated. Since the length of a game is stochastic, it is important to control for the number of periods in a game when assessing whether the duration of coalitions is statistically different across treatments. To do so, we run an OLS regression on pairs of treatments where the dependent variable is the number of periods a durable coalition persists. The independent variables are the treatment (public communication or private communication) and the length of a game. The results in Table 5 indicate that introducing private communication increases the duration of a Majoritarian coalition by about 2 periods (with respect to the baseline with no communication at the average game length). ${ }^{27}$ Introducing private communication does not affect the duration of a Universal coalition, but introducing public communication increases the duration of Universal coalitions by about 3 periods (with respect to the baseline with no communication at the average game length). ${ }^{28}$

\footnotetext{
${ }^{27}$ The average game lengths (including the first period of the games) are 9 periods, 11 periods, and 8 periods for Baseline, Private Communication, and Public Communication, respectively.

${ }^{28}$ With experienced subjects (games 2-4), there are no Majoritarian coalitions with public communication. This can also be seen from Table 4: there are 9 Majoritarian status quo allocations and none of them persists. When using the whole sample, public communication does not affect the duration of either Majoritarian or Universal coalitions.
} 


\subsection{Analysis of Conversations}

The analysis presented above shows marked differences in allocations and coalitions between the baseline treatment with no communication and the treatments with private or public communication. To shed light on the mechanism underlying these differences, we analyze the messages exchanged in the communication treatments. We answer the following questions: How does private communication differ from public communication? What aspects of communication (volume, participants, direction, content) matter for the allocation of resources and the persistence of a durable coalition?

Subjects took advantage of the opportunity to communicate with other committee members. Communication preceded most proposals, especially at the beginning of a game: the fraction of periods with some conversation is $62 \%$, and $92 \%$ of committees communicated in the first period of a game. Moreover, $99 \%$ of committees have conversations in at least one period of the game. Table 6 gives the breakdown of communication by treatment and presents the average number of messages (overall as well as by sender and by recipient) for each treatment.

\begin{tabular}{lcc}
\hline \hline & Private Comm. & Public Comm. \\
\hline Any Message Sent (All Periods) & $66 \%^{\dagger}$ & $55 \%$ \\
Any Message Sent (Period 1) & $91 \%$ & $93 \%$ \\
Mean Number of Messages (All Periods) & $4.22^{\dagger}$ & 3.36 \\
From Proposers & $1.51^{\dagger}$ & 1.20 \\
From Non-Proposers & $2.70^{\dagger}$ & 2.15 \\
Non-Proposer $\rightarrow$ Proposer & 1.67 & - \\
Non-Proposer $\rightarrow$ Non-Proposer & 1.03 & - \\
Mean Number of Messages (Period 1) & $6.00^{\dagger}$ & 3.86 \\
\hline \hline
\end{tabular}

Table 6: Use of communication. $\dagger$ : significant difference from public communication according to WilcoxonMann-Whitney tests $(p<0.05)$.

\section{FINDING 5: Subjects communicate more frequently privately than publicly.}

There is more communication with private than with public communication (66\% versus $55 \%$ ), and the average number of messages exchanged in a period is higher with private than with public communication (4.22 versus 3.36 in all periods; 6.00 vs. 3.86 in the first period of a game). These differences are statistically significant. ${ }^{29}$

Table 6 includes two other interesting results: a proposer does not send a different number

\footnotetext{
${ }^{29}$ When including inexperienced subjects, the only statistically significant difference is for number of messages exchanged in the first period of a game.
} 
of messages than a non-proposer in either treatment. ${ }^{30}$ Also, when communication is private, non-proposers are more likely to contact the proposer than the other non-proposer. ${ }^{31}$ One interpretation is that non-proposers believe that communicating with the member who has the power to set the agenda is more fruitful in terms of steering the decision of the committee towards what they prefer. This is in line with the experimental literature on unrestricted communication in bilateral bargaining, which has highlighted the positive effect of asking for more resources (Andreoni and Rao 2011). We next investigate whether this is also true in our dynamic multilateral bargaining setting.

\section{FINDING 6: With private communication, receiving more messages is corre- lated with receiving more resources; sending more messages is correlated with receiving less resources.}

Table 7 reports the results of Tobit regressions where the dependent variable is the allocation to proposers and non-proposers at the end of a period and the independent variables are the allocation to this member in the status quo at the beginning of that period and the number of messages sent or received by this member in the period. For public communication there is no effect of the initial status quo or the number of messages for either the proposer or the non-proposers. One interpretation of this is that, in the first game, the subjects learn to play the universal allocation, perhaps as guided by a norm of fairness, and, in games 2-4, play according to what they have learned.

In the private communication treatment, the sender can choose the recipients of his/her message, so in Table 7 we distinguish between the numbers of messages sent (received) by the role of the recipient (sender). For all treatments and all roles, sending a message is negatively correlated with the allocation received at the end of the period, whereas receiving a message is positively correlated with the allocation. For proposers, sending a private message might involve building a coalition by attracting the support of a non-proposer, whereas receiving a message might involve non-proposers competing to be in a coalition. With the exception of the number of messages sent from a non-proposer to a non-proposer, these correlations are statistically significant in the private communication treatment. ${ }^{32}$ Receiving communication

\footnotetext{
${ }^{30}$ There are two non-proposers and only one proposer in each period and in each committee, and Table 6 reports the average number of messages sent by the two non-proposing members in a period. The average number of messages sent by a single non-proposing member in a period is 1.35 with private communication and 1.08 with public communication. These averages are not statistically distinguishable from the average number of messages sent by a proposer in the respective treatments.

${ }^{31}$ The difference (0.64) between the average number of messages sent by a non-proposer to a proposer and the average number of messages sent by a non-proposer to a non-proposer is statistically significant at the $1 \%$ confidence level.
}

${ }^{32}$ When using the whole sample, the coefficient for Own Allocation in SQ in the last two columns is positive 


\begin{tabular}{|c|c|c|c|c|}
\hline \multirow{2}{*}{ Own Allocation in SQ } & \multicolumn{4}{|c|}{ Dependent Variable: Own Allocation } \\
\hline & $\begin{array}{c}0.70^{* * *} \\
(0.06)\end{array}$ & $\begin{array}{c}0.57^{* * *} \\
(0.07)\end{array}$ & $\begin{array}{l}-0.02 \\
(0.11)\end{array}$ & $\begin{array}{c}-0.03 \\
(0.05)\end{array}$ \\
\hline \# Messages to Non-Prop & $\begin{array}{c}-1.35^{* * *} \\
(0.42)\end{array}$ & $\begin{array}{l}-0.49 \\
(0.51)\end{array}$ & & \\
\hline \# Messages from Non-Prop & $\begin{array}{c}1.13^{* * *} \\
(0.29)\end{array}$ & $\begin{array}{l}1.04^{* *} \\
(0.47)\end{array}$ & & \\
\hline \# Messages to Prop & & $\begin{array}{l}-0.68^{*} \\
(0.39)\end{array}$ & & \\
\hline \# Messages from Prop & & $\begin{array}{c}2.44^{* * *} \\
(0.58)\end{array}$ & & \\
\hline \# Messages to All Others & & & $\begin{array}{l}-0.12 \\
(0.09)\end{array}$ & $\begin{array}{l}-0.06 \\
(0.07)\end{array}$ \\
\hline \# Messages from Any Other & & & $\begin{array}{c}0.07 \\
(0.10)\end{array}$ & $\begin{array}{c}0.02 \\
(0.02)\end{array}$ \\
\hline Constant & $\begin{array}{c}9.36^{* * *} \\
(1.93)\end{array}$ & $\begin{array}{c}4.10^{* * *} \\
(1.44)\end{array}$ & $\begin{array}{c}20.94^{* * *} \\
(2.31)\end{array}$ & $\begin{array}{c}20.25^{* * *} \\
(0.90)\end{array}$ \\
\hline Role & Proposer & Non-Proposer & Proposer & Non-Proposer \\
\hline Treatment & Private & Private & Public & Public \\
\hline Observations & 472 & 944 & 252 & 504 \\
\hline$R^{2}$ & 0.094 & 0.051 & 0.001 & 0.001 \\
\hline
\end{tabular}

Table 7: Tobit regressions. Standard errors clustered by committees in parentheses. ${ }^{*} p<0.10,{ }^{* *} p<0.05$, $* * * \quad p<0.01$. An observation is a committee member in a period.

might increase the resources to oneself because senders use private messages with the goal of being included in a coalition. In what follows, we explore this possibility by investigating the content of messages.

In analyzing the content of communication, we search for expressions or keywords and assign messages containing them to one or more semantic domain. First, we identify all messages that include a numerical suggestion on how to divide the 60 tokens among the three committee members. In particular, we classify messages that contain '30-30' as 'Suggest 3030-0'; messages that contain '20-20-20' as 'Suggest 20-20-20'; and messages that contain any other triplet of numbers summing to 60 as 'Suggest Other Allocation'. ${ }^{33}$ Second, we identify the messages that contain at least one word or expression about fairness ('Lobby for Fairness'), about obtaining resources for oneself ('Lobby for Oneself'), about forming a

and significant at the $1 \%$ confidence level. The coefficient of \# Messages to Non-Prop in the second column is negative and significant at the $10 \%$ confidence level.

\footnotetext{
${ }^{33}$ In identifying messages that belong to the domains 'Suggest 30-30-0' and 'Suggest 20-20-20', we consider all possible variations of these numbers in a message, as '20-20-20', '20/20/20', '202020', '20 20 20', and so on.
} 


\begin{tabular}{lccccc|ccc}
\hline \hline & \multicolumn{7}{c|}{ Private Comm. } & \multicolumn{3}{c}{ Public Comm. } \\
\hline & ALL & $\mathrm{P}$ & $\mathrm{NP}$ & $\mathrm{NP} \rightarrow \mathrm{P}$ & $\mathrm{NP} \rightarrow \mathrm{NP}$ & $\mathrm{ALL}$ & $\mathrm{P}$ & $\mathrm{NP}$ \\
Lobby Oneself & $0.02^{\dagger}$ & 0.02 & 0.02 & 0.03 & 0.02 & 0.01 & 0.01 & 0.01 \\
Lobby Fairness & 0.06 & $0.08^{\dagger \dagger}$ & 0.04 & 0.06 & 0.03 & 0.05 & 0.04 & 0.06 \\
Form Coalition & $0.12^{\dagger}$ & $0.14^{\dagger \dagger}$ & 0.11 & 0.12 & 0.11 & 0.02 & 0.02 & 0.02 \\
History & 0.02 & 0.03 & 0.02 & 0.02 & 0.03 & 0.01 & 0.02 & 0.01 \\
Suggest 20-20-20 & 0.06 & 0.07 & 0.05 & 0.05 & 0.05 & 0.04 & 0.03 & 0.05 \\
Suggest 30-30-0 & $0.04^{\dagger}$ & $0.06^{\dagger \dagger}$ & 0.03 & 0.04 & 0.03 & 0.01 & 0.01 & 0.01 \\
Suggest Other & $0.03^{\dagger}$ & $0.05^{\dagger \dagger}$ & 0.02 & 0.03 & 0.02 & 0.01 & 0.00 & 0.01 \\
\hline \hline
\end{tabular}

Table 8: Fraction of messages belonging to semantic domain. ALL is for all members; $\mathrm{P}$ is for proposers; NP is for non-proposers; $\mathrm{NP} \rightarrow \mathrm{P}$ is for non-proposers speaking to proposer; $\mathrm{NP} \rightarrow \mathrm{NP}$ is for non-proposers speaking to non-proposer. $\dagger$ : significant difference with public communication treatment according to Wilcoxon-Mann-Whitney tests $(p<0.05)$. $\dagger \dagger$ : significant difference with non-proposers in same treatment according to Wilcoxon-Mann-Whitney tests $(p<0.05)$.

coalition ('Form a Coalition') and about the history of play ('History'). ${ }^{34}$ Table 8 shows the frequency of messages related to each of these semantic domains by treatment, by sender and by receiver. ${ }^{35}$

\section{FINDING 7: The content of messages differs across treatments and across types of senders.}

Private messages are more likely than public messages to be about lobbying for oneself, forming a coalition, or proposing an allocation of resources other than 20-20-20. Messages advocating fairness and proposing an even allocation of resources have similar frequencies in both communication treatments. In both treatments, proposers are more likely than nonproposers to advocate for fairness (in private messages with words; in public messages, with

\footnotetext{
${ }^{34}$ Examples of words or expressions that lead a message to be classified as 'Lobby for Fairness' are 'equal', 'fair', 'give him'. Examples of words or expressions that lead a message to be classified as 'Lobby for Oneself' are 'give me', 'help me', 'I want'. Examples of words or expressions that lead a message to be classified as 'Form a Coalition' are 'alliance', 'trust', 'team', 'loyal', 'deal'. Examples of words or expressions that lead a message to be classified as 'History' are 'betrayal', 'deviation', 'punish', 'cheated', 'lied'. Some messages were classified as belonging to multiple semantic domains, for example: 'any chance you could make it a little more fair? help me out!'. The messages that do not belong to any of these semantic domains have mostly to do with timing, wanting the game to end, discussing the rules of the experiment, and interpreting the incentives. The complete list of words and expressions for each of these semantic domains is provided in Appendix D. We searched both algorithmically and manually. The full transcripts of the communication and the classifications are available from the authors upon request.

${ }^{35}$ When using the whole sample, we observe the fraction of messages about History (0.03 vs. 0.02) and Suggest $20-20-20$ (0.06 vs. 0.04$)$ is significantly larger with private than with public communication. With private communication, non-proposers are more likely to send messages about Lobbying for Fairness $(0.06$ vs. 0.03), Suggest 30-30-0 (0.04 vs. 0.02) and Suggest Other (0.04 vs. 0.02) to the proposer than to the other non-proposer. The other comparisons are unchanged.
} 
a numerical suggestions to divide the tokens evenly) and to make a precise suggestion for an allocation. The content of private messages sent by non-proposers is not statistically different when directed to the proposer or to the other non-proposer.

Finally, we investigate whether we can relate the content of communication to actual allocations and coalitions. Tables 9, 10 and 11 show how the probability of observing Universal allocations, the formation of a durable coalition, and the dissolution of a durable coalition are correlated with the use of the communication channel and the presence of messages belonging to each semantic domain in a period. The corresponding tables in Appendices A and B are consistent with Tables 9-11, indicating that the findings have a degree of robustness to the categorization of allocations and a weaker definition of durable coalitions. ${ }^{36}$ Our experimental design does not allow us to exogenously manipulate the amount and content of conversations. For this reason, these tables do not identify whether the messages help in attaining a particular allocation or coalition or whether the messages are used to explain an action taken on other grounds.

\section{FINDING 8: The content of messages is correlated with allocation types, as well as with the formation and the dissolution of durable coalitions.}

Table 9 shows penalized maximum likelihood estimates for the probability a committee chooses a Universal, rather than Majoritarian, allocation in a period. ${ }^{37}$ The variable 'Any Messages' is a dummy variable which takes value 1 if at least one message is exchanged in a period. It is included in the regressions to distinguish between periods in which no message was sent and periods with messages. The other independent variables are dummies which take value 1 if at least one message in each of the semantic domains is exchanged. With private communication, the estimates for the whole sample (in column 1) and for experienced subjects (in column 3) are quite similar: messages advocating fairness and suggesting a 20-20-20 allocation are positively correlated with universal allocations, whereas messages suggesting a 30-30-0 allocation are negatively correlated with universal allocations. The latter is consistent with the messages supporting Majoritarian allocations. With private

\footnotetext{
${ }^{36}$ In Table 9, the dependent variable, the independent variables and the subsamples analyzed in each column do not depend on the definition of a durable coalition. For this reason, there is no counterpart of Table 9 in Appendix B, that is, there is no robustness check considering weak rather than strong durable coalitions.

${ }^{37}$ Observations in Table 9 do not include periods with Dictatorial allocations. In Tables 9-11, we use penalized maximum likelihood (Firth 1993) rather than logistic estimates in order to deal with the small sample bias arising from the reduced number of periods with non-universal allocations when communication is public and subjects are experienced (less than 5\%). For Table 9, when computing logistic estimates, 'Form a Coalition' 'Suggest 20-20-20' and 'Suggest 30-30-0' are dropped for the last column because positive values perfectly predict a universal allocation. Apart from this, the results are unchanged if we use logistic regressions with standard errors clustered by committee.
} 


\begin{tabular}{lcccc}
\hline \hline & \multicolumn{4}{c}{$\operatorname{Pr}\{$ Universal Allocation $\}$} \\
\hline Any Messages & $-0.75^{* * *}$ & $-0.84^{* * *}$ & -0.39 & $-1.15^{*}$ \\
Lobby for Oneself & $(0.20)$ & $(0.30)$ & $(0.25)$ & $(0.69)$ \\
& -0.07 & -0.48 & 0.34 & -0.76 \\
Lobby for Fairness & $0.71^{* * *}$ & $1.65^{* * *}$ & $0.80^{* * *}$ & $(1.01)$ \\
& $(0.27)$ & $(0.60)$ & $(0.31)$ & 0.39 \\
Form a Coalition & -0.32 & 0.24 & $-0.57^{* *}$ & $0.93)$ \\
& $(0.22)$ & $(0.57)$ & $(0.26)$ & $(1.45)$ \\
History & -0.11 & $-1.13^{* *}$ & 0.12 & -1.02 \\
& $(0.31)$ & $(0.55)$ & $(0.37)$ & $(0.98)$ \\
Suggest 20-20-20 & $1.40^{* * *}$ & $1.40^{* *}$ & $1.55^{* * *}$ & 1.54 \\
Suggest 30-30-0 & $(0.27)$ & $(0.61)$ & $(0.33)$ & $(1.46)$ \\
Constant & $-0.98^{* * *}$ & -0.90 & $-1.01^{* * *}$ & -0.27 \\
& $(0.30)$ & $(0.84)$ & $(0.34)$ & $(1.61)$ \\
& $0.49^{* * *}$ & $1.98^{* * *}$ & 0.04 & $3.45^{* * *}$ \\
Treatment & $(0.14)$ & $(0.23)$ & $(0.16)$ & $(0.54)$ \\
Subjects & Private & Public & Private & Public \\
Observations & All & All & Experienced & Experienced \\
Pseudo $R^{2}$ & 638 & 433 & 450 & 251 \\
\hline \hline
\end{tabular}

Table 9: Penalized maximum likelihood regressions. ${ }^{*} p<0.10,{ }^{* *} p<0.05,{ }^{* * *} p<0.01$. An observations is a committee in a period. Observations do not include periods with Dictatorial allocations.

communication and experienced subjects the coefficient of 'Form a Coalition' is negatively correlated with the presence of a Universal allocation, which is consistent with the word 'coalition' and the semantic domain interpreted as pertaining to a coalition of size two.

For public communication, the estimates for the whole sample (in column 2) and for experienced subjects (in column 4) are somewhat different. With experienced subjects (that is, in games 2-4), the content of public communication is uncorrelated with the probability of observing a Universal allocation, whereas, for the entire sample, the coefficients of Lobby for Fairness and Suggest 20-20-20 are positive and statistically significant and the coefficient of Suggest 30-30-0 is negative and statistically significant. This is consistent with our interpretation of the results from the previous sections: subjects learn to coordinate on and maintain Universal coalitions in the first game and, thereafter, do not need substantive communication, as if following a norm, perhaps established in the first game. Words related to history are uncorrelated or weakly negative correlated with the presence of a Universal allocation, which is consistent with a norm based on altruism, rather than the threat of punishment. 


\begin{tabular}{lccc}
\hline \hline \multicolumn{1}{c}{ Dependent Variable: } & $\operatorname{Pr}\{$ Durable & Coalition & Forms $\}$ \\
\hline Any Message & -0.30 & 0.35 & -0.29 \\
Lobby for Oneself & $(0.52)$ & $(0.56)$ & $(0.99)$ \\
& -0.30 & 0.17 & $2.77^{* *}$ \\
Lobby for Fairness & $(0.64)$ & $(0.67)$ & $(1.26)$ \\
& 0.74 & $0.86^{*}$ & $3.58^{* * *}$ \\
Form a Coalition & $0.95^{* *}$ & $(0.46)$ & $(0.92)$ \\
& $(0.43)$ & 0.09 & -0.82 \\
History & 0.20 & $0.45)$ & $(0.85)$ \\
& $(0.54)$ & $(0.60)$ & $-3.19^{* *}$ \\
Suggest 20-20-20 & 0.01 & 0.57 & $4.61^{* * *}$ \\
& $(0.59)$ & $(0.44)$ & $(0.94)$ \\
Suggest 30-30-0 & $1.16^{* * *}$ & 0.68 & -2.10 \\
Constant & $(0.44)$ & $(0.54)$ & $(1.63)$ \\
& $-2.03^{* * *}$ & $-2.37^{* * *}$ & $-3.42^{* * *}$ \\
Coalition Type & $(0.36)$ & $(0.41)$ & $(0.54)$ \\
Treatment & Majoritarian & Universal & Universal \\
Observations & Private & Private & Public \\
$R^{2}$ & 239 & 211 & 240 \\
\hline \hline
\end{tabular}

Table 10: Penalized maximum likelihood regressions. ${ }^{*} p<0.10,{ }^{* *} p<0.05,{ }^{* * *} p<0.01$. One observation is a committee in a period.

Table 10 relates the formation of durable coalitions to the content of messages. As shown in Table 4, with Public Communication, Majoritarian allocations never persists, so we do not present estimates for this combination of treatment and allocation type. With private communication, lobbying for fairness is positively correlated with the formation of a Universal coalition. Messages associated with the formation of a coalition and suggesting a 30-30-0 allocation are positively correlated with the formation of a Majoritarian coalition, which is consistent with the correlations with experienced subjects in the third column of Table 9. With public communication, suggesting 20-20-20, lobbying for fairness, and lobbying for oneself are positively correlated with the formation of a Universal coalition, while talking about the history of the game is negatively correlated with the formation of such coalitions. ${ }^{38}$

\footnotetext{
${ }^{38}$ When using logistic estimates, in the first column, Lobbying for Fairness is positive and significant at the $10 \%$ level; Form a Coalition is positive and significant at the $1 \%$ level; in the last column, History is negative and significant at the 10\% level; Suggest 30-30-0 is dropped because positive values predict failure perfectly. The other coefficients have the same sign and significance levels. When using the whole sample, in the first column, Form a Coalition is positive and significant at the $1 \%$ level; Lobbying for Fairness and Suggest 20-20-20 are positive and significant at the 5\% level; in the second column, Lobbying for Fairness
} 


\begin{tabular}{lccc}
\hline \hline \multicolumn{1}{c}{ Dependent Variable: } & Pr $\{$ Durable & Coalition Dissolves $\}$ \\
\hline Any Message & 0.87 & 0.85 & 0.19 \\
& $(0.59)$ & $(0.71)$ & $(1.24)$ \\
Lobby for Oneself & 0.12 & $1.89^{* * *}$ & $2.64^{*}$ \\
& $(0.66)$ & $(0.66)$ & $(1.40)$ \\
Lobby for Fairness & -0.02 & 0.50 & 0.67 \\
& $(0.58)$ & $(0.56)$ & $(1.26)$ \\
Form a Coalition & -0.18 & -0.66 & -1.42 \\
& $(0.47)$ & $(0.58)$ & $(1.98)$ \\
History & 0.37 & 0.86 & 1.48 \\
& $(0.60)$ & $(0.66)$ & $(1.30)$ \\
Suggest 20-20-20 & -0.56 & 0.38 & 0.99 \\
& $(0.76)$ & $(0.53)$ & $(1.19)$ \\
Suggest 30-30-0 & $0.87^{*}$ & -1.05 & 0.84 \\
Constant & $(0.48)$ & $(0.92)$ & $(1.84)$ \\
& $-2.72^{* * *}$ & $-3.03^{* * *}$ & $-4.29^{* * *}$ \\
Coalition Type & $(0.49)$ & $(0.55)$ & $(0.82)$ \\
Treatment & Majoritarian & Universal & Universal \\
Observations & Private & Private & Public \\
$R^{2}$ & 239 & 211 & 240 \\
\hline \hline
\end{tabular}

Table 11: Penalized maximum likelihood regressions. ${ }^{*} p<0.10,{ }^{* *} p<0.05,{ }^{* * *} p<0.01$. One observation is a committee in a period.

Finally, Table 11 presents correlations between the content of messages and the dissolution of coalitions. As for the previous table, we do not report estimates for Majoritarian coalitions and Public Communication, because we do not observe any Majoritarian coalition in that treatment. With private communication, lobbying for oneself is positively correlated with the dissolution of a Universal coalition and suggesting a 30-30-0 allocation is positively correlated with the dissolution of a Majoritarian coalition. ${ }^{39}$

In Tables 9-11 with public communication, talking about past behavior is not significantly

is positive and significant at the $5 \%$ level; in the last column, Lobby for Oneself is not significant; History is negative and significant at the 1\% level; Suggest 30-30-0 is negative and significant at the $5 \%$ level. The other coefficients have the same sign and significance levels.

${ }^{39}$ When using logistic estimates, in the first column, Suggest 30-30-0 is positive and significant at the $5 \%$ level; in the last column, Lobby for Oneself is positive and significant at the $5 \%$ level; Form a Coalition and Suggest 30-30-0 are dropped because positive values predict dissolution perfectly. The other coefficients have the same sign and significance levels. When using the whole sample, in the second column, Any Message is positive and significant at the $10 \%$ level; Lobby for Oneself is positive and significant at the $5 \%$ level. In the third column, Any Message is positive and significant at the $5 \%$ level; Lobby for Oneself is not significant. The other coefficients have the same sign and significance levels. 
correlated with universal allocations nor with the dissolution of coalitions in both treatments, and it is negatively correlated with the formation of Universal coalitions. As detailed in Appendix D, we included in the 'History' domain keywords and expressions that can be related to history-dependent strategies: 'betray', 'deviate', 'retaliate', 'cheat', 'lie', 'revenge', 'promise', 'punish' (and words sharing the same root). The findings in Tables 9, 10 and 11 suggest that the emergence and duration of Universal allocations or coalitions are not due to the threat of punishment using history-dependent strategies. The findings in these tables are consistent with universal outcomes being supported by a norm of fairness. However, the extent to which the effect of these terms is causal cannot be gauged by our experimental design because the content of messages is endogenously chosen by the subjects. ${ }^{40}$

\section{Conclusions}

In this paper, we present a laboratory experiment to study durable coalitions in a dynamic legislative bargaining setting. Our experimental treatment is the opportunity of subjects to communicate with one another. The three treatments are: committees that cannot communicate, committees that can engage in private conversations before a proposal is made, and committees that can engage in public conversations before a proposal is made. Communication is viewed as a mechanism for coordinating on particular allocations and coalitions.

With regard to the research questions posed in the Introduction, we find that the opportunity to communicate has a significant impact on the formation of coalitions and, consequently, on how resources are allocated. When communication is possible, durable coalitions emerge more frequently and last longer. Compared to the treatment with no communication, private communication increases coordination on majoritarian coalitions and decreases coordination on universal coalitions, whereas public communication has the opposite effect.

To shed light on the mechanism underlying these differences, we analyze the messages exchanged in the communication treatments. Subjects who can communicate privately engage in more lobbying for themselves and are more likely to discuss the formation of a coalition or to suggest a non-universal allocation of the resources than do subjects who can only commu-

\footnotetext{
${ }^{40}$ In Appendices A and B, we show robustness checks for Table 10 and Table 11 considering an alternative classification of allocations and an alternative definition of coalition. These correlations are consistent across all three sets of analyses: the formation of a Majoritarian coalition with Private Communication is positively correlated with Form a Coalition; the formation of a Universal coalition with Public Communication is positively correlated with Lobby for Fairness and Suggest 20-20-20; the dissolution of a Universal coalition with Private Communication is positively correlated with Lobby for Oneself. The positive correlation between Suggest 30-30-0 and the formation of a Majoritarian coalition in Private Communication and the negative correlation between History and the dissolution of a Universal coalition in Public Communication are robust to the alternative definition of allocations but not to the alternative definition of coalitions.
} 
nicate publicly. Messages related to fairness and suggesting a 20-20-20 division are positively correlated with Universal allocations in both communication treatments.

The experimental evidence suggests a role for social interaction and communication in theories of dynamic legislative bargaining and points theorists to a fruitful direction for future research. This role may be in affecting a norm of fairness, in reducing strategic uncertainty or the fear of exclusion from a less-than-universal coalition, and in coordinating players' strategies to attain particular types of equilibria. Our results suggest that not only the existence of a communication channel but also the mode of communication matters in coordinating on equilibria. Coordination could be reinforced by experience. With private communication, a higher frequency of majoritarian coalitions results as subjects become more experienced, whereas, with public communication, universal coalitions become more frequent.

Because of the absence of theories encompassing communication, this experiment is not a test of the existing theories for a dynamic divide-the-dollar game with communication. Nonetheless, existing theories for the dynamic game with no communication help us understand the incentives present in the experiment. The gap in that understanding pertains to universal coalitions. The modal allocation in the no-communication and public communication treatments is universal, and most of the universal allocations have even sharing among the coalition members. Three explanations of this are consistent with theory. ${ }^{41}$ The first is extreme risk aversion as in the Battaglini and Palfrey (2012) model, but the required risk aversion is so extreme as to be unbelievable in the experimental setting. The second is playerspecific punishments that deter individual subjects from deviating from the equilibrium path to take short-term gains. This takes fairly sophisticated strategies and implicit threats of punishment. As discussed in Section 5.3, messages related to such punishment strategies are uncorrelated with the presence and duration of universal coalitions The third possible explanation is preferences that are not selfish but instead exhibit a degree of altruism that could generate a norm of fairness that supports universal allocations. This explanation is consistent with the overall experimental findings, but experiments designed to identify the foundations of and measure the strength of a norm of fairness are needed before concluding that such a norm explains bargaining outcomes. As Cooper and Kagel (Forthcoming) note in their survey of the empirical finding in sequential (static) legislative bargaining, "more is going on in games of this sort than we currently understand."

\footnotetext{
${ }^{41}$ The universal allocation is also not explained, for example, by the von Neuman-Morgenstern solution concept in cooperative game theory, which selects minimal winning coalitions with allocations of the form 30-30-0.
} 


\section{References}

Agranov, Marina and Chloe Tergiman. 2014a. "Communication in Multilateral Bargaining." Journal of Public Economics 118:75-85.

Agranov, Marina and Chloe Tergiman. 2014b. "Transparency versus Back-Room Deals in Bargaining." mimeo.

Andreoni, James and Justin M. Rao. 2011. "The Power of Asking: How Communication Affects Selfishness, Empathy, and Altruism." Journal of Public Economics 95(7):513-520.

Anesi, Vincent and Daniel J Seidmann. 2015. "Bargaining in Standing Committees with an Endogenous Default." Review of Economic Studies 82(4):1-43.

Anesi, Vincent and John Duggan. 2015. "Existence and Indeterminacy of Markovian Equilibria in Dynamic Bargaining Games." mimeo.

Austen-Smith, David. 1990. "Information Transmission in Debate." American Journal of Political Science 34(1):124-152.

Baranski, Andrzej and John H. Kagel. 2015. "Communication in Legislative Bargaining." Journal of the Economic Science Association 1(1):59-71.

Baron, David P. 2016. "Simple Dynamics of Legislative Bargaining: Coalitions and Proposal Power." mimeo.

Baron, David P. and John A. Ferejohn. 1989. "Bargaining in Legislatures." American Political Science Review 83(4):1181-1206.

Baron, David P. and T. Renee Bowen. 2015. "Dynamic Coalitions." mimeo.

Battaglini, Marco and Thomas R. Palfrey. 2012. "The Dynamics of Distributive Politics." Economic Theory 49(3):739-777.

Binmore, Ken and Jon X. Eguia. 2016. "Bargaining with Outside Options." mimeo.

Bowen, T. Renee and Zaki Zahran. 2012. "On Dynamic Compromise." Games and Economic Behavior 76(2):391-419.

Brandts, Jordi and David J. Cooper. 2007. "It's What You Say, Not What You Pay: An Experimental Study of Manager-Employee Relationships in Overcoming Coordination Failure." Journal of the European Economic Association 5(6):1223-1268. 
Charness, Gary and Martin Dufwenberg. 2006. "Promises and Partnership." Econometrica 74(6):1579-1601.

Charness, Gary and Martin Dufwenberg. 2011. "Participation." The American Economic Review 101(4):1211-1237.

Chen, Ying and Hülya Eraslan. 2014. "Rhetoric in legislative bargaining with asymmetric information." Theoretical Economics 9(2):483-513.

Cooper, David J. and John H. Kagel. Forthcoming. Bargaining Experiments. In The Handbook of Experimental Economics, Vol. 2, ed. John H. Kagel and Alvin E. Roth. Princeton University Press.

Croson, Rachel, Terry Boles and J Keith Murnighan. 2003. "Cheap Talk in Bargaining Experiments: Lying and Threats in Ultimatum Games." Journal of Economic Behavior 83 Organization 51(2):143-159.

Dal Bo, Pedro. 2005. "Cooperation under the Shadow of the Future: Experimental Evidence from Infinitely Repeated Games." American Economic Review 95(5):1591-1604.

Diermeier, Daniel and Pohan Fong. 2011. "Legislative Bargaining with Reconsideration." Quarterly Journal of Economics 126(2):947-985.

Diermeier, Daniel and Rebecca Morton. 2005. Experiments in Majoritarian Bargaining. In Social Choice and Strategic Decisions: Essays in Honor of Jeffrey S. Banks, ed. David A. Smith and John Duggan. Springer pp. 201-226.

Diermeier, Daniel, Roderick I. Swaab, Victoria H. Medvec and Mary C. Kern. 2008. "The Micro-Dynamics of Coalition Formation." Political Research Quarterly 61(3):484-501.

Diermeier, Daniel and Sean Gailmard. 2006. "Self-Interest, Inequality, and Entitlement in Majoritarian Decision-Making." Quarterly Journal of Political Science 1(4):327-350.

Duffy, John and Jack Ochs. 2009. "Cooperative Behavior and the Frequency of Social Interaction." Games and Economic Behavior 66(2):785-812.

Firth, David. 1993. "Bias Reduction of Maximum Likelihood Estimates." Biometrika 80(1):27-38.

Frechette, Guillaume R. 2009. "Learning in a Multilateral Bargaining Experiment." Journal of Econometrics 153(2):183-195. 
Frechette, Guillaume R., John H. Kagel and Massimo Morelli. 2005a. "Behavioral Identification in Coalitional Bargaining: An Experimental Analysis of Demand Bargaining and Alternating Offers." Econometrica 73(6):1893-1937.

Frechette, Guillaume R., John H. Kagel and Massimo Morelli. 2005b. "Gamson's Law versus Non-cooperative Bargaining Theory." Games and Economic Behavior 51(2):365-390.

Frechette, Guillaume R., John H. Kagel and Massimo Morelli. 2005c. "Nominal Bargaining Power, Selection Protocol, and Discounting in Legislative Bargaining." Journal of Public Economics 89(8):1497-1517.

Frechette, Guillaume R., John H. Kagel and Massimo Morelli. 2012. "Pork versus Public Goods: An Experimental Study of Public Good Provision within a Legislative Bargaining Framework." Economic Theory 49(3):779-800.

Frechette, Guillaume R., John H. Kagel and Steven F. Lehrer. 2003. "Bargaining in Legislatures: An Experimental Investigation of Open versus Closed Amendment Rules." American Political Science Review 97(2):221-232.

Frechette, Guillaume R and Sevgi Yuksel. 2013. "Infinitely Repeated Games in the Laboratory: Four Perspectives on Discounting and Random Termination." mimeo.

Goeree, Jacob K and Leeat Yariv. 2011. "An Experimental Study of Collective Deliberation." Econometrica 79(3):893-921.

Kalandrakis, Tasos. 2004. "A Three-Player Dynamic Majoritarian Bargaining Game." Journal of Economic Theory 116(2):294-322.

Kalandrakis, Tasos. 2010. "Minimum Winning Coalitions and Endogenous Status Quo." International Journal of Game Theory 39:617-643.

Maskin, Eric and Jean Tirole. 2001. "Markov Perfect Equilibrium:: I. Observable Actions." Journal of Economic Theory 100(2):191-219.

McKelvey, Richard D. 1991. An Experimental Test of a Stochastic Game Model of Committee Bargaining. In Contemporary Laboratory Research in Political Economy, ed. Thomas R. Palfrey. Ann Arbor: University of Michigan Press pp. 139-69.

Murnighan, J Keith and Alvin E Roth. 1977. "The Effects of Communication and Information Availability in an Experimental Study of a Three-Person Game." Management Science 23(12):1336-1348. 
Nunnari, Salvatore. 2016. "Dynamic Legislative Bargaining with Veto Power: Theory and Experiments." mimeo.

Oprea, Ryan, Gary Charness and Daniel Friedman. 2014. "Continuous Time and Communication in a Public-Goods Experiment." Journal of Economic Behavior \& Organization 108:212-223.

Palfrey, Thomas R. and Howard Rosenthal. 1994. "Repeated Play, Cooperation and Coordination: An Experimental Study." Review of Economic Studies 61(3):545-565.

Rapoport, Amnon, Ido Erev and Rami Zwick. 1995. "An Experimental Study of Buyer-Seller Negotiation with One-Sided Incomplete Information and Time Discounting." Management Science 41(3):377-394.

Rapoport, Amnon and James P. Kahan. 1984. "Coalition Formation in a Five-Person Market Game." Management Science 30(3):326-343.

Richter, Michael. 2014. "Fully Absorbing Dynamic Compromise." Journal of Economic Theory 152:92-104.

Roth, Alvin E. 1995. Bargaining Experiments. In The Handbook of Experimental Economics, Vol. 1, ed. John H. Kagel and Alvin E. Roth. Princeton University Press chapter 4, pp. 253-348.

Roth, Alvin E. and J. Keith Murnighan. 1978. "Equilibrium Behavior and Repeated Play of the Prisoner's Dilemma." Journal of Mathematical Psychology 17(2):189-198.

Roth, Alvin E and J Keith Murnighan. 1982. "The Role of Information in Bargaining: An Experimental Study." Econometrica: Journal of the Econometric Society pp. 1123-1142.

Valley, Kathleen, Leigh Thompson, Robert Gibbons and Max H Bazerman. 2002. "How Communication Improves Efficiency in Bargaining Games." Games and Economic Behavior 38(1):127-155. 


\section{Appendix A: Alternative Definition of Allocation Types}

In the text we define as "Dictatorial" allocations that give at least 50 tokens (that is, $83 \%$ of the tokens) to a single committee member; as "Universal" allocations that give at least 10 tokens (that is, $17 \%$ of the tokens) to every member of the committee; and as "Majoritarian" all other allocations. Here, we show that the results are robust to a different definition of Majoritarian and Universal allocations. In particular, we define as Dictatorial allocations that give at least 50 tokens (that is, $83 \%$ of the tokens) to a single member; as Universal allocations that give at least 15 tokens (that is, $25 \%$ of the tokens) to every member; and as Majoritarian allocations that give at least 20 tokens (that is, $33 \%$ of the tokens) to two members and less than 15 to the other. As we did for our original classification, in the latter two categories, we highlight allocations that give members an even number of tokens. For the Universal allocations, this correspond to the allocation (20, 20, 20); for the Majoritarian allocations, this includes all allocations of the form $[b, b, 60-2 b]$ where $b \in(22,30]$.

\begin{tabular}{lccc}
\hline \hline Allocation Type & Baseline & Private & Public \\
\hline DICTATORIAL & $1 \%$ & $5 \%^{\dagger}$ & $1 \%$ \\
MAJORITARIAN & $36 \%$ & $58 \%^{\dagger}$ & $7 \%^{\dagger}$ \\
Even & $18 \%$ & $40 \%^{\dagger}$ & $4 \%^{\dagger}$ \\
Uneven & $17 \%$ & $18 \%$ & $3 \%^{\dagger}$ \\
UNIVERSAL & $56 \%$ & $34 \%^{\dagger}$ & $92 \%^{\dagger}$ \\
Even & $49 \%$ & $31 \%^{\dagger}$ & $90 \%^{\dagger}$ \\
Uneven & $7 \%$ & $4 \%^{\dagger}$ & $2 \%^{\dagger}$ \\
OTHER & $7 \%$ & $3 \%^{\dagger}$ & $1 \%^{\dagger}$ \\
Observations & 328 & 472 & 252 \\
\hline \hline
\end{tabular}

Table 12: Frequency of allocation types by treatment using alternative definition of allocation types. $\dagger$ : significant difference from baseline according to Wilcoxon-Mann-Whitney tests $(p<0.05)$. An observation is a committee in a period. 


\begin{tabular}{|c|c|c|c|}
\hline \multirow[b]{2}{*}{ Allocation Type $\mathbf{T}_{(t-1)}$} & \multicolumn{3}{|c|}{$\operatorname{Pr}\left[\right.$ Allocation $_{(t)}=$ Allocation $\left._{(t-1)}\right]$} \\
\hline & Baseline & Private & Public \\
\hline DICTATORIAL & $0.33(3)$ & $0.38(21)$ & $0.00(1)$ \\
\hline MAJORITARIAN & $0.19(108)$ & $0.56^{\dagger}(250)$ & $0.17(12)$ \\
\hline UNIVERSAL & $0.83(163)$ & $0.79(144)$ & $0.94^{\dagger}(196)$ \\
\hline OTHER & $0.10(21)$ & $0.17(12)$ & $0.00(1)$ \\
\hline Observations & 295 & 427 & 210 \\
\hline
\end{tabular}

Table 13: Persistence of allocation by treatment and allocation type using alternative definition of allocation types. Number of observations for each allocation type and treatment in parentheses. $\dagger$ : significant difference with baseline according to Wilcoxon-Mann-Whitney tests $(p<0.05)$. An observation is a committees in a period.

\begin{tabular}{lcccc}
\hline \hline & \multicolumn{4}{c}{ Dependent Variable: Coalition Duration } \\
\hline Private Communication & $1.68^{* * *}$ & -0.99 & & \\
& $(0.48)$ & $(1.20)$ & $-0.82^{* *}$ & $2.31^{* * *}$ \\
Public Communication & & & $(0.34)$ & $(0.66)$ \\
& & & $-0.06^{*}$ & $0.84^{* * *}$ \\
Game Length & -0.05 & $0.50^{* *}$ & $(0.03)$ & $(0.11)$ \\
& $(0.06)$ & $(0.21)$ & $2.05^{* * *}$ & $-2.74^{* * *}$ \\
Constant & $1.95^{* * *}$ & 0.71 & $(0.43)$ & $(0.93)$ \\
& $(0.67)$ & $(2.11)$ & Baseline & Baseline \\
& Baseline & Baseline & \& Public & \& Public \\
Treatments & Private & \& Private & C Puritarian & Universal \\
Coalition Type & Majoritarian & Universal & Majoritaian & \\
Observations & 52 & 43 & 10 & 62 \\
$R^{2}$ & 0.0562 & 0.3224 & 0.1486 & 0.6383 \\
\hline \hline
\end{tabular}

Table 14: OLS regressions using alternative definition of allocation types. Standard errors clustered by committees in parentheses. ${ }^{*} p<0.10,{ }^{* *} p<0.05,{ }^{* * *} p<0.01$. An observation is a coalition that lasts for at least one period. 


\begin{tabular}{|c|c|c|c|c|}
\hline \multirow{3}{*}{ Any Messages } & \multicolumn{4}{|c|}{$\operatorname{Pr}\{$ Universal Allocation $\}$} \\
\hline & $-0.98 * * *$ & $-0.78 * * *$ & $-0.57^{* *}$ & -0.69 \\
\hline & $(0.21)$ & $(0.27)$ & $(0.25)$ & $(0.55)$ \\
\hline \multirow[t]{2}{*}{ Lobby for Oneself } & $-0.78^{*}$ & -0.50 & -0.80 & -1.10 \\
\hline & $(0.43)$ & $(0.55)$ & $(0.53)$ & $(0.85)$ \\
\hline \multirow[t]{2}{*}{ Lobby for Fairness } & 0.34 & $0.93^{* *}$ & 0.50 & 0.02 \\
\hline & $(0.28)$ & $(0.42)$ & $(0.33)$ & $(0.69)$ \\
\hline \multirow[t]{2}{*}{ Form a Coalition } & $-0.59 * *$ & -0.29 & $-0.86^{* * *}$ & -0.65 \\
\hline & $(0.24)$ & $(0.46)$ & $(0.29)$ & $(0.82)$ \\
\hline \multirow[t]{2}{*}{ History } & -0.07 & $-0.84^{*}$ & 0.05 & -0.87 \\
\hline & $(0.34)$ & $(0.51)$ & $(0.41)$ & $(0.81)$ \\
\hline \multirow[t]{2}{*}{ Suggest 20-20-20 } & $1.34^{* * *}$ & $1.52^{* * *}$ & $1.49^{* * *}$ & 1.32 \\
\hline & $(0.26)$ & $(0.53)$ & $(0.32)$ & $(0.98)$ \\
\hline \multirow[t]{2}{*}{ Suggest 30-30-0 } & $-1.25^{* * *}$ & -0.28 & $-1.25 * * *$ & 0.41 \\
\hline & $(0.35)$ & $(0.82)$ & $(0.41)$ & $(1.52)$ \\
\hline \multirow[t]{2}{*}{ Constant } & $0.35^{* * *}$ & $1.61^{* * *}$ & -0.12 & $2.81^{* * *}$ \\
\hline & $(0.13)$ & $(0.20)$ & $(0.16)$ & $(0.40)$ \\
\hline Treatment & Private & Public & Private & Public \\
\hline Subjects & All & All & Experienced & Experienced \\
\hline Observations & 638 & 433 & 450 & 251 \\
\hline Pseudo $R^{2}$ & 0.1324 & 0.0581 & 0.1165 & 0.0335 \\
\hline
\end{tabular}

Table 15: Penalized maximum likelihood regressions with alternative definition of allocation types. * $p<0.10,{ }^{* *} p<0.05,{ }^{* * *} p<0.01$. An observations is a committee in a period. Observations do not include periods with Dictatorial allocations. 


\begin{tabular}{|c|c|c|c|}
\hline \multicolumn{4}{|c|}{ Dependent Variable: Pr\{Durable Coalition Forms $\}$} \\
\hline \multirow[t]{2}{*}{ Any Message } & -0.21 & 0.31 & -1.03 \\
\hline & $(0.49)$ & $(0.66)$ & $(1.56)$ \\
\hline \multirow[t]{2}{*}{ Lobby for Oneself } & -0.38 & 0.42 & $3.71^{* *}$ \\
\hline & $(0.54)$ & $(1.02)$ & $(1.71)$ \\
\hline \multirow[t]{2}{*}{ Lobby for Fairness } & $0.69^{*}$ & $1.08^{*}$ & $4.79 * * *$ \\
\hline & $(0.41)$ & $(0.57)$ & $(1.48)$ \\
\hline \multirow[t]{2}{*}{ Form a Coalition } & $0.92^{* *}$ & -0.29 & -0.04 \\
\hline & $(0.39)$ & $(0.62)$ & $(0.87)$ \\
\hline \multirow[t]{2}{*}{ History } & 0.18 & 0.11 & $-5.19 * * *$ \\
\hline & $(0.48)$ & $(0.75)$ & $(1.82)$ \\
\hline \multirow[t]{2}{*}{ Suggest 20-20-20 } & -0.15 & $0.90^{*}$ & $5.79 * * *$ \\
\hline & $(0.50)$ & $(0.53)$ & $(1.50)$ \\
\hline \multirow[t]{2}{*}{ Suggest $30-30-0$} & $1.20 * * *$ & 0.58 & -2.23 \\
\hline & $(0.39)$ & $(0.76)$ & $(1.63)$ \\
\hline \multirow[t]{2}{*}{ Constant } & $-2.06^{* * *}$ & $-2.46^{* * *}$ & $-3.74^{* * *}$ \\
\hline & $(0.36)$ & $(0.44)$ & $(0.64)$ \\
\hline Coalition Type & Majoritarian & Universal & Universal \\
\hline Treatment & Private & Private & Public \\
\hline Observations & 275 & 162 & 232 \\
\hline$R^{2}$ & 0.1195 & 0.0982 & 0.5200 \\
\hline
\end{tabular}

Table 16: Penalized maximum likelihood regressions with alternative definition of allocation types. * $p<0.10,{ }^{* *} p<0.05,{ }^{* * *} p<0.01$. An observation is a committee in a period. 


\begin{tabular}{|c|c|c|c|}
\hline \multicolumn{4}{|c|}{ Dependent Variable: $\operatorname{Pr}\{$ Durable Coalition Dissolves $\}$} \\
\hline \multirow[t]{2}{*}{ Any Message } & $1.30^{* *}$ & 0.14 & 0.17 \\
\hline & $(0.62)$ & $(0.85)$ & $(1.26)$ \\
\hline \multirow[t]{2}{*}{ Lobby for Oneself } & -0.11 & $3.47^{* * *}$ & 1.80 \\
\hline & $(0.58)$ & $(1.08)$ & $(1.78)$ \\
\hline \multirow[t]{2}{*}{ Lobby for Fairness } & 0.12 & 0.63 & 1.00 \\
\hline & $(0.48)$ & $(0.77)$ & $(1.16)$ \\
\hline \multirow[t]{2}{*}{ Form a Coalition } & -0.04 & -0.97 & 0.01 \\
\hline & $(0.41)$ & $(0.97)$ & $(1.85)$ \\
\hline \multirow[t]{2}{*}{ History } & 0.53 & 1.00 & -0.35 \\
\hline & $(0.51)$ & $(0.90)$ & $(2.05)$ \\
\hline \multirow[t]{2}{*}{ Suggest 20-20-20 } & -0.60 & 0.76 & 0.94 \\
\hline & $(0.64)$ & $(0.72)$ & $(1.14)$ \\
\hline \multirow[t]{2}{*}{ Suggest 30-30-0 } & 0.38 & 0.65 & 1.48 \\
\hline & $(0.45)$ & $(1.03)$ & $(1.55)$ \\
\hline \multirow[t]{2}{*}{ Constant } & $-3.02^{* * *}$ & $-2.94^{* * *}$ & $-4.26 * * *$ \\
\hline & $(0.55)$ & $(0.55)$ & $(0.82)$ \\
\hline Coalition Type & Majoritarian & Universal & Universal \\
\hline Treatment & Private & Private & Public \\
\hline Observations & 275 & 162 & 232 \\
\hline$R^{2}$ & 0.0334 & 0.1975 & 0.0030 \\
\hline
\end{tabular}

Table 17: Penalized maximum likelihood regressions with alternative definition of allocation types. * $p<0.10,{ }^{* *} p<0.05,{ }^{* * *} p<0.01$. An observation is a committee in a period. 


\section{Appendix B: Weaker Definition of Durable Coalition}

\begin{tabular}{|c|c|c|c|}
\hline Allocation Type $_{(t-1)}$ & \multicolumn{3}{|c|}{$\operatorname{Pr}\left[\right.$ Allocation $\operatorname{Type}_{(t)}=$ Allocation Type $\left._{(t-1)}\right]$} \\
\hline DICTATORIAL & $0.33(3)$ & $0.57(21)$ & - \\
\hline MAJORITARIAN & $0.22(79)$ & $0.71^{\dagger}(219)$ & $0.22(9)$ \\
\hline UNIVERSAL & $0.88(213)$ & $0.86(187)$ & $0.98^{\dagger}(201)$ \\
\hline Observations & 295 & 427 & 210 \\
\hline
\end{tabular}

Table 18: Persistence of allocation by treatment and allocation type using weaker definition of persistence. Number of observations for each allocation type and treatment in parentheses. $\dagger$ : significant difference with baseline according to Wilcoxon-Mann-Whitney tests $(p<0.05)$. An observation is a committees in a period.

\begin{tabular}{lccc}
\hline \hline & \multicolumn{2}{c}{ Dependent Variable: Coalition Duration } \\
\hline Private Communication & $2.73^{* * *}$ & -1.15 \\
& $(0.45)$ & $(1.00)$ & \\
Public Communication & & & $2.10^{* * *}$ \\
& & & $(0.68)$ \\
Game Length & 0.01 & 0.15 & $0.57^{* * *}$ \\
& $(0.07)$ & $(0.11)$ & $(0.15)$ \\
Constant & 1.00 & $3.81^{* * *}$ & -0.74 \\
& $(0.78)$ & $(1.28)$ & $(1.20)$ \\
\hline Treatments & Base \& Private & Base \& Private & Base \& Public \\
Coalition Type & Majoritarian & Universal & Universal \\
Observations & 57 & 69 & 75 \\
$R^{2}$ & 0.1951 & 0.0589 & 0.3055 \\
\hline \hline
\end{tabular}

Table 19: OLS regressions using weaker definition of coalition. Standard errors clustered by committees in parentheses. ${ }^{*} p<0.10,{ }^{* *} p<0.05,{ }^{* * *} p<0.01$. An observation is a coalition that lasts for at least one period. 


\begin{tabular}{|c|c|c|c|}
\hline \multicolumn{4}{|c|}{ Dependent Variable: $\operatorname{Pr}\{$ Durable Coalition Forms $\}$} \\
\hline \multirow[t]{2}{*}{ Any Message } & -0.20 & 0.45 & $1.37^{*}$ \\
\hline & $(0.54)$ & $(0.66)$ & $(0.77)$ \\
\hline \multirow[t]{2}{*}{ Lobby for Oneself } & -0.44 & $1.83^{* * *}$ & 0.12 \\
\hline & $(0.67)$ & $(0.64)$ & $(1.54)$ \\
\hline \multirow[t]{2}{*}{ Lobby for Fairness } & 0.58 & 0.07 & $1.51^{* * *}$ \\
\hline & $(0.49)$ & $(0.52)$ & $(0.55)$ \\
\hline \multirow[t]{2}{*}{ Form a Coalition } & $1.19^{* * *}$ & -0.55 & -1.04 \\
\hline & $(0.46)$ & $(0.53)$ & $(0.86)$ \\
\hline \multirow[t]{2}{*}{ History } & -0.19 & 0.70 & -0.91 \\
\hline & $(0.59)$ & $(0.66)$ & $(1.01)$ \\
\hline \multirow[t]{2}{*}{ Suggest $20-20-20$} & 0.01 & $1.32^{* * *}$ & $1.99 * * *$ \\
\hline & $(0.60)$ & $(0.49)$ & $(0.53)$ \\
\hline \multirow[t]{2}{*}{ Suggest 30-30-0 } & 0.74 & 0.29 & -1.06 \\
\hline & $(0.46)$ & $(0.58)$ & $(1.54)$ \\
\hline \multirow[t]{2}{*}{ Constant } & $-2.17^{* * *}$ & $-2.77^{* * *}$ & $-3.77 * * *$ \\
\hline & $(0.39)$ & $(0.49)$ & $(0.64)$ \\
\hline Coalition Type & Majoritarian & Universal & Universal \\
\hline Treatment & Private & Private & Public \\
\hline Observations & 239 & 211 & 240 \\
\hline$R^{2}$ & 0.1088 & 0.0357 & 0.4260 \\
\hline
\end{tabular}

Table 20: Penalized maximum likelihood regressions using weaker definition of coalition. ${ }^{*} p<0.10,{ }^{* *}$ $p<0.05,{ }^{* * *} p<0.01$. An observation is a committee in a period. 


\begin{tabular}{|c|c|c|c|}
\hline \multicolumn{4}{|c|}{ Dependent Variable: $\operatorname{Pr}\{$ Durable Coalition Dissolves $\}$} \\
\hline \multirow{2}{*}{ Any Message } & 0.50 & 0.18 & -0.52 \\
\hline & $(0.53)$ & $(0.79)$ & $(2.50)$ \\
\hline \multirow[t]{2}{*}{ Lobby for Oneself } & -0.11 & $1.98^{* * *}$ & 3.71 \\
\hline & $(0.74)$ & $(0.72)$ & $(2.56)$ \\
\hline \multirow[t]{2}{*}{ Lobby for Fairness } & -0.56 & 0.17 & 2.17 \\
\hline & $(0.73)$ & $(0.66)$ & $(1.68)$ \\
\hline \multirow[t]{2}{*}{ Form a Coalition } & -0.01 & -0.24 & -0.49 \\
\hline & $(0.49)$ & $(0.65)$ & $(2.14)$ \\
\hline \multirow[t]{2}{*}{ History } & 0.84 & 0.62 & -0.40 \\
\hline & $(0.61)$ & $(0.83)$ & $(1.97)$ \\
\hline \multirow[t]{2}{*}{ Suggest 20-20-20 } & -0.55 & 0.90 & 2.14 \\
\hline & $(0.92)$ & $(0.61)$ & $(1.67)$ \\
\hline \multirow[t]{2}{*}{ Suggest $30-30-0$} & -0.07 & -0.65 & 2.29 \\
\hline & $(0.59)$ & $(0.92)$ & $(1.84)$ \\
\hline \multirow[t]{2}{*}{ Constant } & $-2.33^{* * *}$ & $-3.03 * * *$ & $-5.40 * * *$ \\
\hline & $(0.41)$ & $(0.55)$ & $(1.42)$ \\
\hline Coalition Type & Majoritarian & Universal & Universal \\
\hline Treatment & Private & Private & Public \\
\hline Observations & 239 & 211 & 240 \\
\hline$R^{2}$ & 0.0101 & 0.0821 & 0.0133 \\
\hline
\end{tabular}

Table 21: Penalized maximum likelihood regressions using weaker definition of coalition. ${ }^{*} p<0.10,{ }^{* *}$ $p<0.05,{ }^{* * *} p<0.01$. An observation is a committee in a period. 


\section{Appendix C: Irrelevance of Exogenous Status Quo}

\begin{tabular}{lccc}
\hline \hline \multicolumn{4}{c}{ Dependent Variable: Share Allocated to Member $i$} \\
\hline Share to $i$ in Current SQ (Endogenous) & -0.08 & $0.51^{* *}$ & -0.05 \\
Share to $i$ in Initial SQ (Exogenous) & $(0.23)$ & $(0.20)$ & $(0.09)$ \\
& -0.14 & -0.11 & 0.01 \\
Constant & $(0.13)$ & $(0.09)$ & $(0.02)$ \\
& $24.05^{* * *}$ & $11.24^{* *}$ & $21.00^{* * *}$ \\
Observations & $(3.56)$ & $(4.82)$ & $(1.96)$ \\
Period & 99 & 135 & 126 \\
Treatment & 2 & 2 & 2 \\
Pseudo R-Squared & Baseline & Private & Public \\
\hline \hline
\end{tabular}

Table 22: Tobit regressions. Standard errors clustered by committees in parentheses. ${ }^{*} p<0.10$, $* *$ $p<0.05,{ }^{* * *} p<0.01$. When using the whole sample, the coefficients of Share to $i$ in Current SQ in the last two columns are positive and significant at the $1 \%$ confidence level. 


\section{Appendix D: List of Keywords for Semantic Domains}

A message belongs to a class if it contains the following words or expressions:

1. Lobby for Oneself: 'help me', 'help a friend out', 'give(s) me', 'gimme', 'leave me', 'X would be enough for my vote', ' $\mathrm{X}$ is enough for my vote', 'I'll vote for with $\mathrm{X}$ ', 'as long as I get X', 'can I have more', 'let me earn', 'move me up', 'I really need', 'I need', 'I (would) want', 'bump me up', 'I'd be happy if you'.

2. Lobby for Fairness: equal, equally, equality, equitably, equitable, egalitarian, fair, fairly, fairer, fairness, unfair, greedy, greed, justice, 'feel bad', 'felt bad', 'feel kinda bad', 'felt a little bad', 'give him', 'leave him', selfish, even, evenly, evens, balance, balances, balancing, unbalanced, generous, parity, 'let him have', 'for everyone', socialism, distribute, redistribution, distribution, 'move him up'.

3. Form a Coalition: alliance, allied, ally, allying, trust, (un)trustworthy, trusted, team(s), teamwork, teammate, loyal, loyalty, together, deal(s), 'give you', 'gives you', 'giving you', 'help(ing) you', 'each other', unite, promise, commit, collude, colluding, stick(ing), cooperating, cooperation, reciprocate, 'I will/'ll do the same', 'I do the same', 'can I count on your vote?', 'support my proposal', 'bump you up', 'bring you up', 'between us', pact, 'both of us', collaborate, accept.

4. History: threat, betrayal, betray, betrayed, betraying, deviate(s), deviation(s), defect(s), defector, revenge, retaliation, retaliate, cheated, cheater, cooperated, punishment, punishing, punished, penalize, lie(s), lied, gave (excluded 'if I/you/he gave'), accepted, 'helped you', promised, 'stuck to the alliance', 'stuck with the status quo', cooperated, voted, proposed, supported. 


\section{Appendix E: Instructions (Private Communication)}

This is an experiment in committee decision making. The instructions are simple, and if you follow them carefully and make good decisions, you can earn a considerable amount of money which will be paid to you in cash at the end of the experiment. The currency in this experiment is called tokens. The total amount of tokens you earn in the experiment will be converted into US dollars using the rate of 20 Tokens $=\$ 1$. In addition, you will get a $\$ 5$ participation fee.

This experiment consists of 4 Matches. In every Match you will each be randomly and anonymously matched with two other participants in the room to form committees of three. Each member of the committee will be assigned a committee member number (from 1 to 3). Your committee as well as your committee member number will remain the same within a Match but will change between Matches. Each Match consists of a number of Rounds.

The number of Rounds in a Match is not fixed. Instead, it depends on chance. After each Round in a Match, there is an $80 \%$ chance that another Round will take place. In other words, after each Round there is an $80 \%$ chance that the Match continues, and a $20 \%$ chance that the Match ends.

After each round, there is an $80 \%$ probability that the match will continue for at least another round. Specifically, after each round, whether the match continues for another round will be determined by a random number between 1 and 100 generated by the computer. If the number is lower than or equal to 80 the match will continue for at least another round, otherwise it will end. For example, if you are in round 2, the probability that there will be a third round is $80 \%$ and if you are in round 9 , the probability that there will be a tenth round is also $80 \%$. That is, at any point in a match, the probability that the match will continue is $80 \%$. However, you will play every match in blocks of 4 rounds. At the end of each block you will learn if the match ended in the previous block of 4 rounds or not. If it has not, you will play another block of 4 rounds. If the match has ended in this block, you will see in which round it had actually ended.

In each Round, your committee has 60 tokens to allocate among the three members. At the beginning of the first Round of a Match, the computer randomly selects an initial allocation and displays it on your computer as what we call the Status Quo. One of the members of your committee then is selected at random by the computer to be the Proposer for this Round. The Proposer makes a Proposal for an alternative allocation he would like the committee to choose. This proposal can be any three numbers (including 0s) that add to exactly 60. Once the Proposer in a Round has submitted his Proposal, all members of his committee will vote for the Status Quo or the Proposal. If the Proposal receives a 
simple majority of votes (that is, two or more members in your committee vote in favor of the Proposal), then the Proposal passes and each of you in the committee will receive the number of tokens indicated in the Proposal. If the Proposal is rejected instead, each of you receives the number of tokens given in the Status Quo.

Each round, the match continues for another round with probability $80 \%$. When you move to another round of the same match, your committee's allocation decision in the previous Round becomes the Status Quo in the new Round. Therefore, if the original Status Quo received a majority of the votes in the previous round, it continues as the Status Quo in this new round. But if the Proposal in the previous round received a majority of the votes, it becomes the Status Quo in this new round. The proposal and voting process then follows the same rules as before. A committee member will be selected at random to submit an allocation proposal and a vote is taken between the Status Quo and the Proposal.

Once a match ends, a new Match will begin in which you will be randomly assigned to a new committee. If your committee finishes early, you may have to wait for other committees to finish. Remember that in each Match you are randomly matched into committees and committee member numbers are randomly assigned. Thus, your committee member number is likely to vary from Match to Match, while it remains the same within a Match from Round to Round. Once five matches have been completed, the experiment is over. Your total earnings for the experiment are the sum of your earnings over all rounds before each match ends. You will NOT receive any payoff from rounds you've played within a block after the match had ended.

Now please, have a look at the screen in front of the room.

\section{[SHOW SLIDE 1]}

This is the first screen you will see in each round of a match if you are not the proposer for this round. You have been assigned by the computer to a committee of 3 members, and assigned a committee member number 1, 2, or 3. This committee number stays the same for all rounds of this match, but will change with each match. The initial Status Quo, which was determined randomly by the computer, is displayed in blue. Information specific to you is highlighted in red. One of the committee members $(1,2$, or 3$)$ has been randomly selected to be the Proposer for this round in your committee.

In each Round, before the Proposer submits his proposal, members of your committee will have the opportunity to communicate with each other using the chat box. The communication is structured as follows. On the left of the screen, you will see a box that displays all messages sent to you. You will not see whether the other members have communicated among themselves. In the box below that one, you can type your own message and send it to 
a particular member of the committee. To select the member to receive your message, simply click on the button that corresponds to the member to whom you want to send the message. The chat box will be available until the Proposer submits his proposal or 120 seconds have passed, whatever comes first. At that moment the chat box will be disabled.

\section{[SHOW SLIDE 2]}

This is the first screen you will see in each round of a match if you are the proposer for this round. A proposal consists of three numbers, A1, A2, and A3, where A1 is the allocation to committee member 1, A2 is the allocation to committee member 2, and A3 is the allocation to committee member 3. The three allocations must add to exactly 60 . To make a proposal, enter the 3 numbers using your keyboard and then click on the confirm button. If you enter three numbers that do not add to 60 or if you enter a negative allocation, the computer will ask you to try again. As everyone else, you have the opportunity to communicate with any other committee member before you submit your proposal, using the same chat interface we described before.

\section{[SHOW SLIDE 3]}

Once the Proposer has submitted his allocation proposal, you will see a similar screen where a vote is taken between this Proposal and the Status Quo. Your payoffs for the Status Quo and the Proposal are displayed in red in the table on your screen. You will now have an opportunity to vote for the Status Quo or the Proposal by clicking on the corresponding button.

\section{[SHOW SLIDE 4]}

Finally, a screen similar to this will summarize the voting results. Each committee member's vote is displayed in the table along with the outcome and your payoff. This marks the end of the round.

\section{[SHOW SLIDE 5]}

You will automatically continue on to the next round if you're within a block of 4 rounds. If you're at the end of a block, you will see a screen similar to this one. The computer generated random numbers for all rounds. If all the random numbers are less than 80, this means that the match continues, and you will start another block of 4 rounds. Otherwise, the match will be considered to have ended in the first round where the random number 
was greater than 80 . You will only receive payoffs for rounds before the match ended. Once you're informed that a match had ended, you will be randomly assigned to a new committee.

In the second round of a match, you will see a screen similar to this: you have the same committee member number as in the first round, and the members of your committee all stay the same. The round 2 Status Quo is whatever alternative received a majority of the votes in the first round. The proposal and voting process then follows the same rules as before. A committee member will be selected at random to submit an allocation proposal and a vote is taken between the Status Quo and the Proposal. 